\title{
Experimental study on improving the accuracy of marine gravimetry by combining moving-base gravimeters with GNSS antenna array
}

\author{
Zhimin Shi ${ }^{1,2}$, Junjian Lang ${ }^{1}$, Xinghui Liang ${ }^{1 *}$, Zhibo Zhou ${ }^{1,2}$, Aizhi Guo ${ }^{1}$ and Lintao Liu ${ }^{1}$
}

\begin{abstract}
The gravity field is one of the Earth's basic physical fields. The geoid can be calculated and the tectonic activity underground can be inversed by gravity anomaly. With the development of various ship-borne gravimeters and navigation technology, including the Global Navigation Satellite System (GNSS) and Strapdown Inertial Navigation System (SINS), the precision of marine gravimetry has been significantly improved (achieve or better than $1 \mathrm{mGal}$ ). Errors arising from calculations of the correction term have become the main source of gravity measurement errors. At present, the traditional approach is to deploy a GNSS antenna, connect the GNSS antenna to the gravimeter, record the realtime position through data acquisition software, and then use this position to calculate the gravity correction item afterward. Two errors are inevitable. (1) The GNSS antenna position error is large. The pseudorange point positioning method is generally used to obtain real-time GNSS antenna positions, and the positioning accuracy is poor compared with that of precise point positioning. (2) The position coordinates of the gravimeter contain systematic errors related to the ship's attitude. In this paper, a joint experiment including GNSS antenna arrays and ship-borne gravimeters was designed to evaluate the measurement accuracy via repeat lines on the same ship. The experimental results show the following: (1) attitude accuracies of $0.0299^{\circ}$ for the yaw angle, $0.0361^{\circ}$ for the pitch angle, and $0.1671^{\circ}$ for the roll angle can be obtained at baseline lengths of 25 and $4 \mathrm{~m}$. (2) The GNSS antenna array has an obvious role in determining the point acceleration in the low-frequency band $(0-0.01 \mathrm{~Hz})$ and the point position and velocity in the high-frequency band $(0.01-1 \mathrm{~Hz})$. (3) The vertical position eccentricity causes an absolute error of $1 \mathrm{mGal}$ and a relative error of $10^{-1}$ mGal in gravity measurements and can be corrected by the GNSS antenna array method. (4) Using a GNSS antenna array can obviously improve the measurement accuracy of an instrument with a precision equaling or exceeding 1 $\mathrm{mGal}$, but cannot obviously improve that to an instrument with poor precision ( $2 \mathrm{mGal}$ or below).
\end{abstract}

Keywords: Marine gravimetry, GNSS antenna array, Moving-base gravimeter, Attitude

*Correspondence: Ixh_whigg@asch.whigg.ac.cn

1 State Key Laboratory of Geodesy and Earth's Dynamics, Innovation Academy for Precision Measurement Science and Technology, Chinese Academy of Sciences, Wuhan 430077, China

Full list of author information is available at the end of the article

\begin{abstract}
Introduction
The gravity field is one of the Earth's most important physical fields; and all of humankind lives within and is influenced by the gravity field. It is well known that the ocean covers $70 \%$ of the Earth's surface. With the application of satellite altimetry, the marine gravity field can be inverted efficiently. However, the data obtained through satellite altimetry are sometimes insufficient for establishing a highly accurate geoid model because of their low
\end{abstract}


spatial resolution and low accuracy (Sandwell and Smith 1997; Ebbing et al. 2013; Zhu et al. 2019). Therefore, highprecision dynamic gravimetry is important and necessary (Liu et al. 2017).

Marine gravimetry was developed after terrestrial gravimetry. Vening Meinesz (1929) first measured the gravity field at sea in 1923 with a precision of 4-5 mGal; he used two pendulums with the same amplitude but opposite phases to correct the influence of horizontal acceleration. He also investigated the relationship between gravity anomalies and tectonic activity. Subsequently, many instruments appeared using pendulums (Hu et al. 2017). In the 1950s, Lacoste (1967) and Lacoste and Bowles (1982) developed the first gravimeter with a stable platform utilizing a zero-length spring as the sensing unit. Ouyang et al. (2013) conducted repeated line and crossing point tests on 5 sea-air gravimeters carried by the same Y-8 fixed-wing aircraft, and the results showed that the Russian GT-1A airborne gravimeter had the best comprehensive performance and accuracy. Cai et al. (2017) analyzed the error characteristics of the strapdown gravimeter SAG-ZW. Yuan et al. (2020) selective analyzed the error characteristics of different types of gravimeters with different principles. Yuan finds that GT-2M gets the best performance in the rough sea condition compares with the other five gravimeters (SAG-2M, CHZ-II, SGA-WZ, ZL11, and L\&R). The precision of 5 gravimeters (except $L \& R$ ) is less than $0.5 \mathrm{mGal}$. With the development of associated hardware and data processing methods, the precision of gravity measurements continues to increase (Ishihara et al. 2018; Hwang et al. 2014). After obtaining specific force observations, two fundamental steps must be performed to obtain accurate gravity values. The first step is various error corrections, such as Eötvös corrections, vertical acceleration corrections, and free air corrections. The accuracy of the correction directly affects the gravity observation. Accordingly, this paper will focus on methods for applying these corrections. The second step is low-pass filtering, which is important because gravity data are composed of low-frequency signals, and thus, the noise amplitude is generally several times that of the true gravity signal. A finiteimpulse response (FIR) filter, a common low-pass filter, is often used to restore the gravity signal (Liang 2012; Ouyang 2013; Saha et al. 2012; Hehl 1992). However, this paper will not focus on the low-pass filtering of gravity data.

Eötvös derived the formula for the Eötvös correction in 1919, after which Harlan (1968) provided another rigorous formula in which the Global Positioning System (GPS)-derived east-west or north-south velocity can be used directly. The free air correction and normal gravity correction are related to the normal elliptic parameters (physical geodesy), for which there are strict formulas. Zheleznyal and Mikhailov (2012) found that the accuracy of the GNSS-derived height is insufficient when employed for the free air correction. Thus, they deployed a GNSS receiver on a fixed base near the route of a gravity survey and applied the 1996 Earth Gravitational Model (EGM-96) to transform ellipsoidal heights into orthometric heights; accordingly, a higher precision was obtained. However, this method is not practical when the region to be surveyed is far from land.

Most of the above-mentioned corrections are related to or derived from position data. At present, GNSS systems are the most commonly used approach for measuring position data, and the coordinates of the antenna can be calculated conveniently. However, the coordinates of instruments in the laboratory cannot be obtained directly, and taking the antenna position as the instrument position can produce errors in the correction calculations (Huang 1995). Sun et al. (2003) analyzed the eccentricity correction method in the airborne gravity survey with attitude sensor and concluded that the attitude angle accuracy should be better than $0.3^{\circ}$ to obtain sufficient eccentricity correction accuracy. The eccentricity correction method of gravity measurement has been mentioned all the time, but few people have analyzed the specific influence of eccentricity correction on different gravimeters and different corrections in detail. Alternatively, the position of a gravimeter installed indoors can be calculated if we can obtain the attitude of the vessel, the position of the GNSS antenna and the baseline between the antenna and instrument; this process is called an eccentricity correction. The attitude of the vessel can be measured by a SINS or determined by several GNSS antennas (no fewer than 3) mounted on the surveying vessel (Lavrov et al. 2017; Varble et al. 2020). This paper will compare the accuracy and error corrections of two different methods to compute the position: using the positions of GNSS antennas and using the position of a gravimeter after an eccentricity correction.

\section{Shipborne gravimetry and error budget Methodology for measuring and correcting the gravity field}

The theory employed for surveying the gravity field is Newton's second law, and the equation is:

$$
\delta_{\mathrm{g}}=f_{\mathrm{U}}-\dot{v}_{\mathrm{U}}+\delta_{\mathrm{a}_{\mathrm{E}}}-\gamma,
$$

where $\delta_{\mathrm{g}}$ is the gravity anomaly, which is located on the geoid; $f_{\mathrm{U}}$ is the specific force in the vertical direction output by the gravimeter; $\dot{v}_{U}$ is the vertical acceleration of the gravimeter at the moment when obtaining $f_{\mathrm{U}} ; \delta_{\mathrm{a}}$ is the Eötvös correction, which is related to the velocity of 
the gravimeter; and $\gamma$ is the normal gravity value, which is located on the geoid.

However, in relative gravity measurements, the following formula is more commonly used:

$$
\delta_{\mathrm{g}}=g_{\mathrm{b}}+\left(f_{\mathrm{U}}-f_{\mathrm{U}}^{0}\right)-\dot{v}_{\mathrm{U}}+\delta_{\mathrm{a}_{\mathrm{H}}}+\delta_{\mathrm{a}_{\mathrm{E}}}+\delta_{\mathrm{a}_{\mathrm{F}}}+\delta_{\mathrm{a}_{\mathrm{K}}}-\gamma,
$$

where $g_{\mathrm{b}}$ is the gravity anomaly at the gravity benchmark; $f_{\mathrm{U}}^{0}$ is the mean specific force in the vertical direction at the gravity benchmark; $\delta_{\mathrm{aH}}$ is the horizontal correction; $\delta_{\mathrm{aF}}$ is the free air correction, which is related to the orthometric heights; $\delta_{\mathrm{a}_{\mathrm{K}}}$ is the drift correction(Jekeli 2012; Wang et al. 2018; Dodson et al. 1997).

The formula of the Eötvös correction is expressed as follows (Harlan 1968; Sun 2004):

$$
\delta_{\mathrm{aE}}=\left(1+\frac{h}{a}\right)\left(2 \omega v_{\mathrm{E}} \cos \varphi+\frac{\mathrm{v}^{2}}{\mathrm{a}}\right)-\frac{f}{a}\left(v^{2}-\cos ^{2} \varphi\left(3 v^{2}-2 \nu_{\mathrm{E}}^{2}\right),\right.
$$

where $(x, y, z)$ are the coordinates of the Earth-fixed reference system; $N$ is the curvature radius of the unitary circle of the Earth at the coordinate point; $e$ is the Earth's first eccentricity:

$$
\left\{\begin{array}{l}
\alpha=-\tan ^{-1}\left(\frac{-x_{13, n} \sin \beta \sin \gamma-y_{13, n} \sin \beta \cos \gamma+z_{13, n} \cos \beta}{x_{13, n} \cos \gamma-y_{13, n} \sin \gamma}\right) \\
\beta=\tan ^{-1}\left(\frac{z_{12, n}}{\sqrt{x_{12 n}^{2}+y_{12 n}^{2}}}\right) \\
\gamma=\tan ^{-1}\left(\frac{x_{12, n}}{y_{12, n}}\right)
\end{array},\right.
$$

where $v(\mathrm{~m} / \mathrm{s})$ is the velocity of the gravimeter; $\nu_{\mathrm{E}}$ is the velocity on the east-west component; $\omega$ is the Earth's angular velocity of rotation; $f$ is the first oblateness of the ellipsoid; $a$ is the semimajor axis of the ellipsoid.

The velocity $(v)$ and acceleration $(\dot{v})$ are calculated by taking the derivative of the position using the following equations:

$$
\left\{\begin{array}{c}
v=\frac{\mathrm{dr}}{\mathrm{dt}} \\
\dot{v}=\frac{\mathrm{dv}}{\mathrm{dt}}
\end{array}\right.
$$

In the corrections mentioned above, $\dot{v}_{\mathrm{U}}, \delta_{\mathrm{aH}}, \delta_{\mathrm{aE}}, \delta_{\mathrm{aF}}, \delta_{\mathrm{aK}_{\mathrm{K}}}$ and $\gamma$ are related to the instrument position. There is a large body of literature that studies their formulas, which will not be introduced here. Their differences before and after the correction are compared in "Experimental design and data processing" section.

Methodology for calculating the position of the gravimeter Generally, the coordinates of GNSS antennas are geographic coordinates comprising the latitude $(\varphi)$, longitude $(\lambda)$ and ellipsoidal height $(\mathrm{h})$. These coordinates are converted into a spatial Cartesian coordinate system under an Earth-fixed reference system using the following equations:

$$
C_{n}^{b}=\left[\begin{array}{ccc}
\cos \alpha \cos \gamma+\sin \alpha \sin \beta \sin \gamma & -\cos \alpha \sin \gamma+\sin \alpha \sin \beta \cos \gamma & -\sin \alpha \cos \beta \\
\cos \beta \sin \gamma & \cos \beta \cos \gamma & \sin \beta \\
\sin \alpha \cos \gamma-\cos \alpha \sin \beta \sin \gamma & -\sin \alpha \sin \gamma+\cos \alpha \sin \beta \cos \gamma & \cos \alpha \cos \beta
\end{array}\right],
$$
using the following formula: reference system.

where $\alpha$ is the roll angle, $\beta$ is the pitch angle, $\gamma$ is the yaw angle and $\left(x_{i j}, y_{i j}, \mathrm{z}_{i j}\right)_{n}$ is the baseline vector from antenna $i$ to antenna $j$ in the navigation coordinate system. Subscript $e, n, b$ represents the Earth-fixed coordinate system, the navigation coordinate system, and the body coordinate system, respectively. The detailed derivation process can be found in the literature (Cai et al. 2018; Liu and $\mathrm{Ou}$ 2003; Aleshechkin 2011; Zhang and Hao 2017).

After obtaining the attitude angle, the position of a gravimeter installed indoors can be easily calculated

$$
\left[\begin{array}{l}
x_{\mathrm{g}} \\
y_{\mathrm{g}} \\
z_{\mathrm{g}}
\end{array}\right]_{\mathrm{e}}=\left[\begin{array}{l}
x_{\mathrm{a}} \\
y_{\mathrm{a}} \\
z_{\mathrm{a}}
\end{array}\right]_{\mathrm{e}}+\left(C_{e}^{n}\right)^{T}\left(C_{n}^{b}\right)^{T}\left[\begin{array}{c}
x_{\mathrm{ag}} \\
y_{\mathrm{ag}} \\
z_{\mathrm{ag}}
\end{array}\right]_{\mathrm{b}}
$$

where $(x, y, z)_{e}$ are the coordinates in the Earth-fixed coordinate system, the subscript $g$ indicates the position of the gravimeter, the subscript $a$ indicates the position of the antenna; $\left(x_{\mathrm{ag}}, y_{\mathrm{ag}}, \mathrm{z}_{\mathrm{ag}}\right)^{T}{ }_{b}$ is the baseline vector from the antenna to the gravimeter; $\left(C_{n}^{b}\right)^{T}$ is the rotation matrix from the body coordinate system to the navigation coordinate system, and $\left(C_{e}^{n}\right)^{T}$ is the rotation matrix from the navigation coordinate system to the Earth-fixed 


$$
C_{e}^{n}=\left[\begin{array}{ccc}
-\sin \lambda & \cos \lambda & 0 \\
-\cos \lambda \sin \varphi & -\sin \lambda \sin \varphi & \cos \varphi \\
\cos \lambda \cos \varphi & \sin \lambda \cos \varphi & \cos \varphi
\end{array}\right]
$$

\section{Error analysis of the eccentricity correction Error of the attitude angle}

First, we take the derivative with respect to the $(x, y, z)$ of Eq. (6):
Hence, the accuracies of the two horizontal angles $\alpha$ and $\beta$ are related to the vertical positional accuracy of the antenna and the distance of the baseline. Similarly, the yaw accuracy is related to the horizontal positional accuracy of the antenna and the equivalent distance of the baseline. In reality, the distance of the baseline on the ship can range from 10 to $80 \mathrm{~m}$ or more. Using the GNSS differential positioning method, we can obtain a horizontal positional accuracy on the millimeter or centimeter

$$
\left\{\begin{array}{c}
d_{\alpha}=\frac{-\sin \beta \sin \gamma}{\left(1+Q^{2}\right) S} d_{x_{13, n}}+\frac{-\sin \beta \cos \gamma}{\left(1+Q^{2}\right) S} d_{y_{13, n}}+\frac{\cos \beta}{\left(1+Q^{2}\right) S} d_{z_{13, n}} \\
+\frac{-x_{13, n} \cos \beta \sin \gamma-y_{13, n} \cos \beta \cos \gamma}{\left(1+Q^{2}\right) S} d_{\beta} \\
+\frac{-x_{13, n} \sin \beta \cos \gamma+y_{13, n} \sin \beta \sin \gamma}{\left(1+Q^{2}\right) S} d_{\gamma} \\
d_{\beta}=\frac{\left(x_{12, n}^{2}+y_{12, n}^{2}\right) d_{z_{12}, n}-x_{12, n} z_{12, n} d_{x_{12, n}}-y_{12, n} z_{12, n} d_{y_{12, n}}}{\left(x_{12, n}^{2}+y_{12, n}^{2}+z_{12, n}^{2}\right) \sqrt{x_{12, n}^{2}+y_{12, n}^{2}}} \\
d_{\gamma}=\frac{d_{x_{12, n}+d_{y_{12, n}}^{2}}^{s_{12}}}{s_{12}}
\end{array}\right.
$$

where $d_{u}$ means differentiate with respect to variable $\mathrm{u}$, in the actual situation, it also means the error of the variable; $s_{12}(\mathrm{~m})$ is the distance from antenna 1 to antenna $2, S$ is the distance from antenna 3 to baseline $s_{12}$ equal to $x_{13, n} \cos \gamma-\mathrm{y}_{13, \mathrm{n}} \sin \gamma$, and $\mathrm{Q}$ is an auxiliary quantity that is quite small, where $Q=\frac{-x_{13, n} \sin \beta \sin \gamma-\mathrm{y}_{13, \mathrm{n}} \sin \beta \cos \gamma+\mathrm{z}_{13, \mathrm{n}} \cos \beta}{x_{13, n} \cos \gamma-\mathrm{y}_{13, \mathrm{n}} \sin \gamma}$.

In the real world, $Q, d_{\alpha}, d_{\beta}, d_{\beta}$ and $z_{12, n} \ll x_{12, n} \approx y_{12, n}<s$. $\left(\approx\right.$ means that $x_{12, n}$ is of the same order of magnitude as $\left.y_{12, n}\right)$. Thus, Eq. (10) is simplified to the following:

$$
\left\{\begin{array}{rl}
d_{\alpha} & \approx \frac{d_{z_{13, n}}}{S} \\
d_{\beta} & \approx \frac{d_{z_{12, n}}}{s_{12}} \\
d_{\gamma} & =\frac{d_{x_{12, n}}^{2}+d_{y_{12, n}}^{2}}{s_{12}}
\end{array} .\right.
$$

scale and a vertical positional accuracy on the centimeter scale (Dong et al. 2020). Then, we can forecast accuracies of approximately $0.01^{\circ}$ for the yaw angle, $0.1^{\circ}$ for the pitch angle and $0.2^{\circ}$ for the roll angle.

\section{Error of the eccentricity correction}

For convenience, an accuracy analysis is carried out in the navigation coordinate system. Equation (7) can be rewritten as follows:

$$
\left[\begin{array}{l}
x_{\mathrm{g}} \\
y_{\mathrm{g}} \\
z_{\mathrm{g}}
\end{array}\right]_{n}=\left[\begin{array}{l}
x_{\mathrm{a}} \\
y_{\mathrm{a}} \\
z_{\mathrm{a}}
\end{array}\right]_{n}+\left(C_{n}^{b}\right)^{T}\left[\begin{array}{l}
x_{\mathrm{ag}} \\
y_{\mathrm{ag}} \\
z_{\mathrm{ag}}
\end{array}\right]_{b} .
$$

The error of the eccentricity correction clearly consists of two parts: the GNSS antenna position error and the attitude angle error. The emphasis here is on the latter. We take the derivative of Eq. (12) with respect to the attitude angle:

$$
\left\{\begin{array}{c}
d_{x_{\mathrm{g}, \mathrm{h}}}=\left[(-\sin \alpha \cos \gamma+\cos \alpha \sin \beta \sin \gamma) x_{\mathrm{ag}, \mathrm{b}}+(\cos \alpha \cos \gamma+\sin \alpha \sin \beta \sin \gamma) z_{\mathrm{ag}, \mathrm{b}}\right] d_{\alpha} \\
+\left(\sin \alpha \cos \beta \sin \gamma \mathrm{x}_{\mathrm{ag}, \mathrm{b}}-\sin \beta \sin \gamma \mathrm{y}_{\mathrm{ag}, \mathrm{b}}-\cos \alpha \cos \beta \sin \gamma \mathrm{z}_{\mathrm{ag}, \mathrm{b}}\right) d_{\beta} \\
+\left[(-\cos \alpha \sin \gamma+\sin \alpha \sin \beta \cos \gamma) x_{\mathrm{ag}, \mathrm{b}}+\cos \beta \cos \gamma y_{\mathrm{ag}, \mathrm{b}}-(\sin \alpha \sin \gamma+\cos \alpha \sin \beta \cos \gamma) z_{\mathrm{ag}, \mathrm{b}}\right] d_{\gamma} \\
d_{y_{\mathrm{g}, \mathrm{h}}}=\left[(\sin \alpha \sin \gamma+\cos \alpha \sin \beta \cos \gamma) x_{\mathrm{ag}, \mathrm{b}}-(\cos \alpha \sin \gamma+\sin \alpha \sin \beta \cos \gamma) z_{\mathrm{ag}, \mathrm{b}}\right] d_{\alpha} \\
+\left(\sin \alpha \cos \beta \cos \gamma \mathrm{x}_{\mathrm{ag}, \mathrm{b}}-\sin \beta \cos \gamma \mathrm{y}_{\mathrm{ag}, \mathrm{b}}+\cos \alpha \cos \beta \cos \gamma \mathrm{z}_{\mathrm{ag}, \mathrm{b}}\right) d_{\beta} \\
+\left[(-\cos \alpha \cos \gamma-\sin \alpha \sin \beta \sin \gamma) x_{\mathrm{ag}, \mathrm{b}}-\cos \beta \sin \gamma \mathrm{y}_{\mathrm{ag}, \mathrm{b}}-(\sin \alpha \cos \gamma+\cos \alpha \sin \beta \sin \gamma) \mathrm{z}_{\mathrm{ag}, \mathrm{b}}\right] d_{\gamma} \\
d_{z_{\mathrm{g}, \mathrm{n}}}=\left(-\cos \alpha \cos \beta \mathrm{x}_{\mathrm{ag}, \mathrm{b}}-\sin \alpha \cos \beta \mathrm{z}_{\mathrm{ag}, \mathrm{b}}\right) d_{\alpha}+\left(\sin \alpha \sin \beta \mathrm{x}_{\mathrm{ag}, \mathrm{b}}+\cos \beta \mathrm{y}_{\mathrm{ag}, \mathrm{b}}-\cos \alpha \sin \beta \mathrm{z}_{\mathrm{ag}, \mathrm{b}}\right) d_{\beta} .
\end{array}\right.
$$



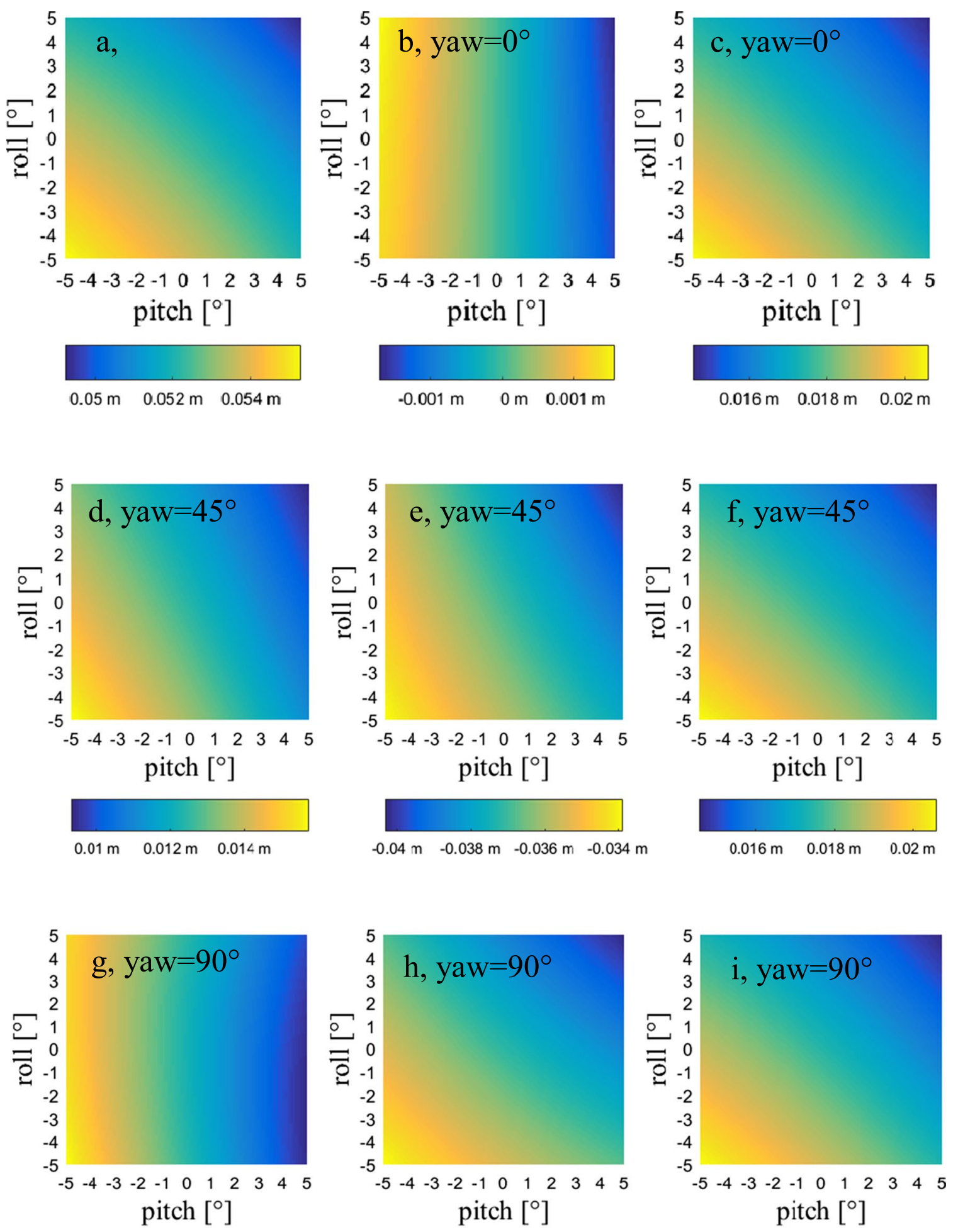

$-0.036 \mathrm{~m}-0.035 \mathrm{~m}-0.034 \mathrm{~m}$
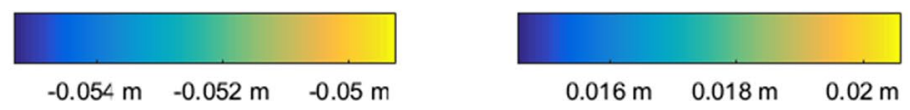

Fig. 1 Errors of the eccentricity correction varying with the attitude angle caused by the attitude angle error. $\mathbf{a}$, $\mathbf{d}$ and $\mathbf{g}$ show the east-west position errors of the eccentricity correction; $\mathbf{b}, \mathbf{e}$, and $\mathbf{g}$ show the north-south position errors of the eccentricity correction; and $\mathbf{c}, \mathbf{f}$, and $\mathbf{i}$ show the elevation position errors of the eccentricity correction. The baseline is taken as $(10,20,10)$, and the attitude angle error is set to $0.1^{\circ}$ 
Table 1 Maximum eccentricity correction errors with different attitude angle errors

\begin{tabular}{lll}
\hline Attitude angle error $\left({ }^{\circ}\right)$ & $\begin{array}{l}\text { Maximum horizontal error } \\
(\mathbf{m})\end{array}$ & $\begin{array}{l}\text { Maximum } \\
\text { vertical error } \\
(\mathbf{m})\end{array}$ \\
\hline 0.1 & 0.055 & 0.02 \\
0.2 & 0.11 & 0.04 \\
0.3 & 0.165 & 0.06 \\
\hline
\end{tabular}

Table 2 Sensors and their position on the ship

\begin{tabular}{lccr}
\hline Sensors name & $\boldsymbol{x}(\mathbf{m})$ & $\boldsymbol{y}(\mathbf{m})$ & $\boldsymbol{z}(\mathbf{m})$ \\
\hline Antenna 1 & 7.471 & 33.857 & 4.197 \\
Antenna 2 & -6.710 & 53.401 & 12.728 \\
Antenna 3 & -2.572 & 54.585 & 12.946 \\
SAG-2M & -1.904 & 41.500 & 0.185 \\
GT-2M & -1.944 & 47.260 & 0.714 \\
L\&R & -0.827 & 45.462 & -2.478 \\
\hline
\end{tabular}

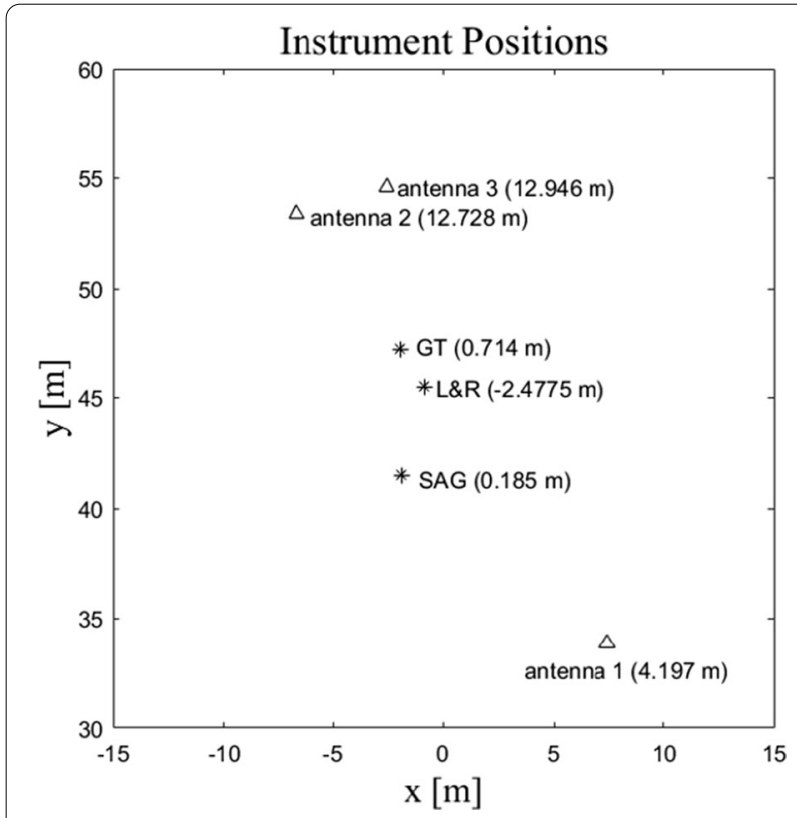

Fig. 2 Positions of the GNSS antennas and gravimeters in the body coordinate system that the origin of coordinates is set on the deck and the $y$-axis points to the bow and the $x$-axis points to starboard. A total station was set up at the origin of coordinates to measure the coordinate center of each instrument. The numbers in parentheses represent the elevation, triangles represent GNSS antennas, and stars represent gravimeters

Each error is related to nine different quantities: three attitude angles, their errors, and three baseline coordinates. Thus, to simplify the above, we employ the baseline $(10 \mathrm{~m}, 20 \mathrm{~m}, 10 \mathrm{~m})$ and analyze three different yaw angles $\left(0^{\circ}, 45^{\circ}, 90^{\circ}\right)$ to determine the error distribution characteristics.

As shown in Fig. 1, where the error of each of the three attitude angles is $0.1^{\circ}$ and the baseline is $(10 \mathrm{~m}$, $20 \mathrm{~m}, 10 \mathrm{~m}$ ), the direction of the maximum horizontal position error rotates with the yaw angle, while the vertical position error is independent of the yaw angle. The maximum errors are listed in Table 1.

\section{Experimental design and data processing Gravity and GNSS data}

The data employed in this study are from the 2018 Xiangyanghong No. 06 gravity comparison survey in the South China Sea. Three GNSS antennas were mounted on the exterior of the ship, and three gravimeters, namely, GT-2M (No. 39), SAG-2M and L\&R Air Sea System II (No. S129), were installed on the ship. Their coordinates are shown in Table 2.

It should be noted that the SAG-2M gravimeter is a strapdown gravimeter with a triaxial accelerometer and a triaxial gyroscope that can be used as a SINS. Its corresponding data processing software also uses inertia's integrated navigation algorithm to calculate gravity. SAG-2M gravimeter adopts a high-precision fiber optic gyroscope and a high-precision quartz accelerometer, and the attitude resolution accuracy is better than $0.002^{\circ}$ through inertial /GNSS combined navigation calculation (Table 2).

Figure 2 demonstrates that the GNSS antennas are positioned higher than the gravimeters. Given this allocation of positions, the value of $S$ in Eq. (11) is not long enough to obtain a higher accuracy of roll angle precision. L\&R is installed at a lower height than the other gravimeters. The receiver corresponding to Antenna 1 is a NovAtel PwrPak7. Antennas 2 and 3 correspond to a Trimble $\mathrm{R} 9$ receiver.

There are four repeated ship lines: a north-south line named S1, an east-west line named $\mathrm{H} 1$, and two northwest-southeast lines named X1 and X2. The information of these repeated ship lines is provided in Table 3. The location on the map is shown in Fig. 3. In Fig. 4, thirty-one crossing points were selected for subsequent accuracy assessment.

In the following text, $\mathrm{X} 1-2$ denotes the second repeated line of X1.

The roll angle reflects the sea conditions for each route. In Fig. 5, the conditions of the X1 lines are the worst; line $\mathrm{S} 1-1$ is also bad. In contrast, the sea conditions for all X2 lines are good. All H1 lines are not bad (Fig. 6, Table 4).

In Table 4 and Fig. 6, the average velocity and velocity change of each survey line are shown. 
Table 3 Information of the repeated ship lines

\begin{tabular}{llll}
\hline Name & Direction & Number of repeats & Line endpoint $\left.\mathbf{(}^{\circ}\right)$ \\
\hline H1 & E-W & 2 & $(116.834972,18.691314),(114.162026,18.691703)$ \\
S1 & N-S & 3 & $(115.81966,20.399971),(115.819741,17.400011)$ \\
X1 & NW-SE & 3 & $(115.59999,16.515155),(114.150013,19.563549)$ \\
X2 & NW-SE & 3 & $(115.584181,20.736491),(116.880896,18.001463)$ \\
\hline
\end{tabular}

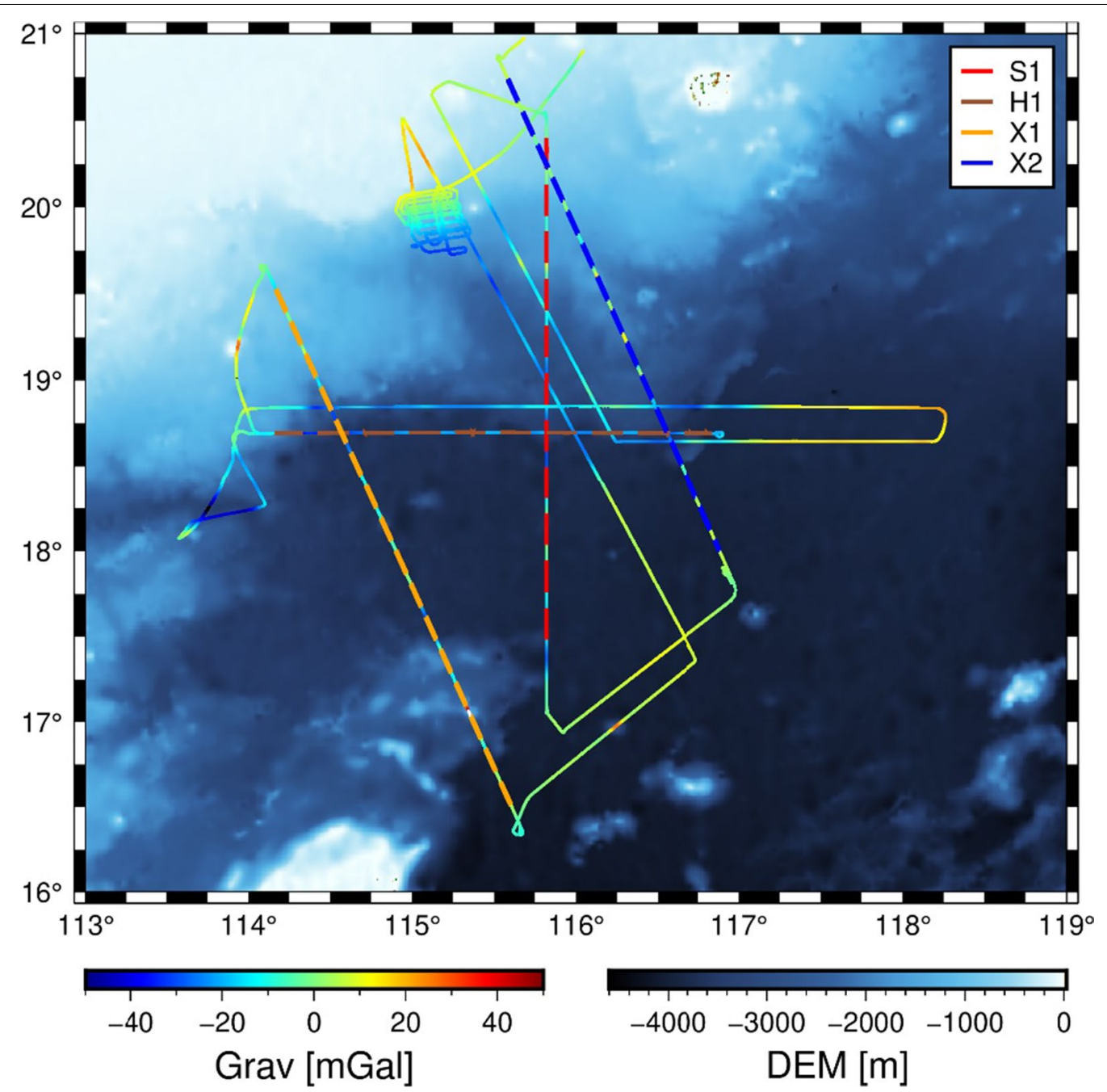

Fig. 3 Ship routes, repeat lines, and bathymetric depth map

\section{Data processing flow}

This test involves the processing of three kinds of data: gravity data, GNSS data and SINS data. Gravimeters provide specific force observations for gravity measurements. SINS instruments can provide position, velocity, acceleration, and attitude information for gravity measurement corrections, but the accuracy of pure inertial navigation data drifts with time, so external reference information must be provided. Data based on GNSS antenna arrays can also provide auxiliary information for gravity measurement corrections, and the accuracy does not drift over time. Differential positioning can obtain the relative position with a high precision (millimeter-level accuracy for the horizontal direction and centimeter-level accuracy for the vertical direction) (Dong et al. 2020) and thus can be used to determine 


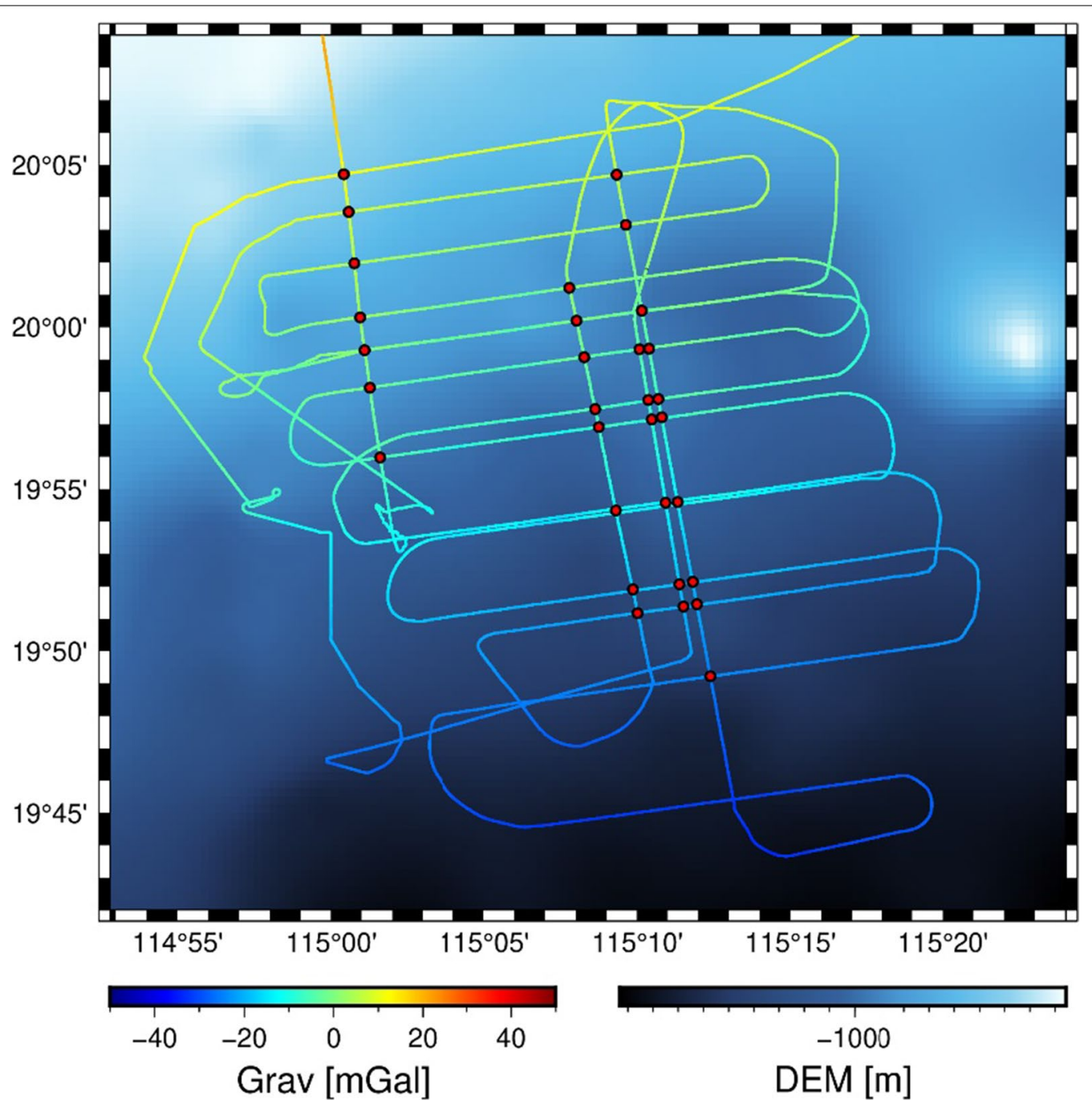

Fig. 4 Grid lines and crossover points

the attitude. Using precise point positioning (PPP) can yield decimeter-level and even centimeter-level absolute dynamic position accuracies (Li et al. 2013, 2010; Heroux and Kouba 2001); hence, PPP can provide the location reference for SINS. Alternatively, the difference between epochs for computing the speed, Doppler observations and carrier phase observations can provide higher-precision velocity and acceleration information (Xu et al. 2015). In this paper, the Moving-Base mode of rtklib (http://gpspp.sakura.ne.jp/rtklib/rtklib.htm) is used to process the multi-antenna GNSS data to get the baseline. The internal coincidence accuracy of the processing results can reach the level of millimeters. The attitude angle is calculated by the baselines and the attitudes calculated by the two methods (SINS and GNSS antenna arrays) are compared. The absolute position is calculated by the PPP method of MG-APP (Xiao et al. 2020), which was able to achieve accuracy on the centimeter to millimeter scale. Finally, a unified 200 s FIR filter was applied to the corrected gravity data (Fig. 7).

\section{Comparison of the multi-antenna attitude with the inertial navigation system attitude}

The GNSS antenna array attitude angles and SINS attitude angles are compared, and error statistics are obtained. In Table 5, the precision of the roll angle is worse than the precision of the yaw and pitch angles because the value of $S$ in Eq. (11) is not long enough, as mentioned in "Gravity and GNSS data" section (Figs. 8, 9, 10).

Attitude determination requires simultaneous observation of at least three GNSS measurements, and the 

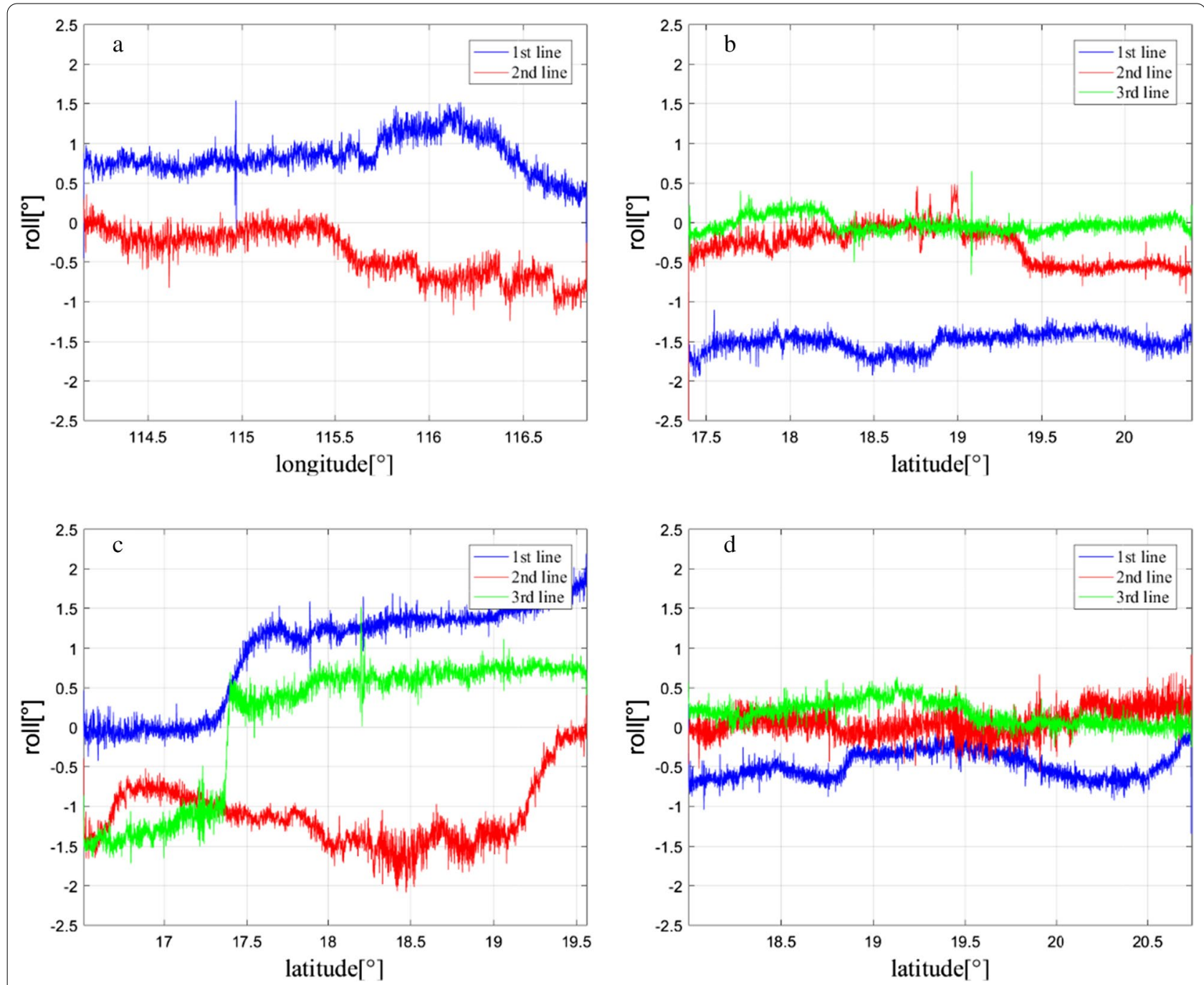

Fig. 5 Roll of each line: a for H1, b for S1, c for X1, and $\mathbf{d}$ for X2. For convenience, the roll angle values were filtered by a 40 s FIR filter

absence of one will cause the attitude to fail to be calculated. During the measurement of the X1-2 survey line, the receiver corresponding to Antenna 2 was not turned on, so the multi-antenna attitude determination could not be carried out. The attitude angle of SINS was used in the subsequent processing of the X1-2 survey line.

\section{Fourier time-frequency analysis of the specific force}

In specific force observations, which are inevitably accompanied by high-frequency noise, the amplitude of noise is often hundreds of times that of the gravity signal, and the noise signal occupies a wide frequency band. In practical processing, a reasonable filter should be designed according to the frequency band of the gravity signal to extract the weak gravity signal. Accordingly, this paper compares the post-processed GNSS antenna array data with the GNSS observation data to recalculate whether the gravity measurement corrections are improved in the corresponding frequency band of gravity signals.

Spectrum analysis of the specific force observations from the entire voyage (Fig. 11, the small windows are enlarged views of the low-frequency band. The small windows are enlarged views of the low-frequency band) reveals that the effective range of the gravity signal is below $0.005 \mathrm{~Hz}$, and there is a wide frequency band without a signal from 0.005 to $0.01 \mathrm{~Hz}$. Therefore, the cutoff frequency of the low-pass filter can be selected within this frequency band, and thus, the focus of the gravity correction calculation should be within $0.005 \mathrm{~Hz}$ (or even $0.003 \mathrm{~Hz}$ ). 

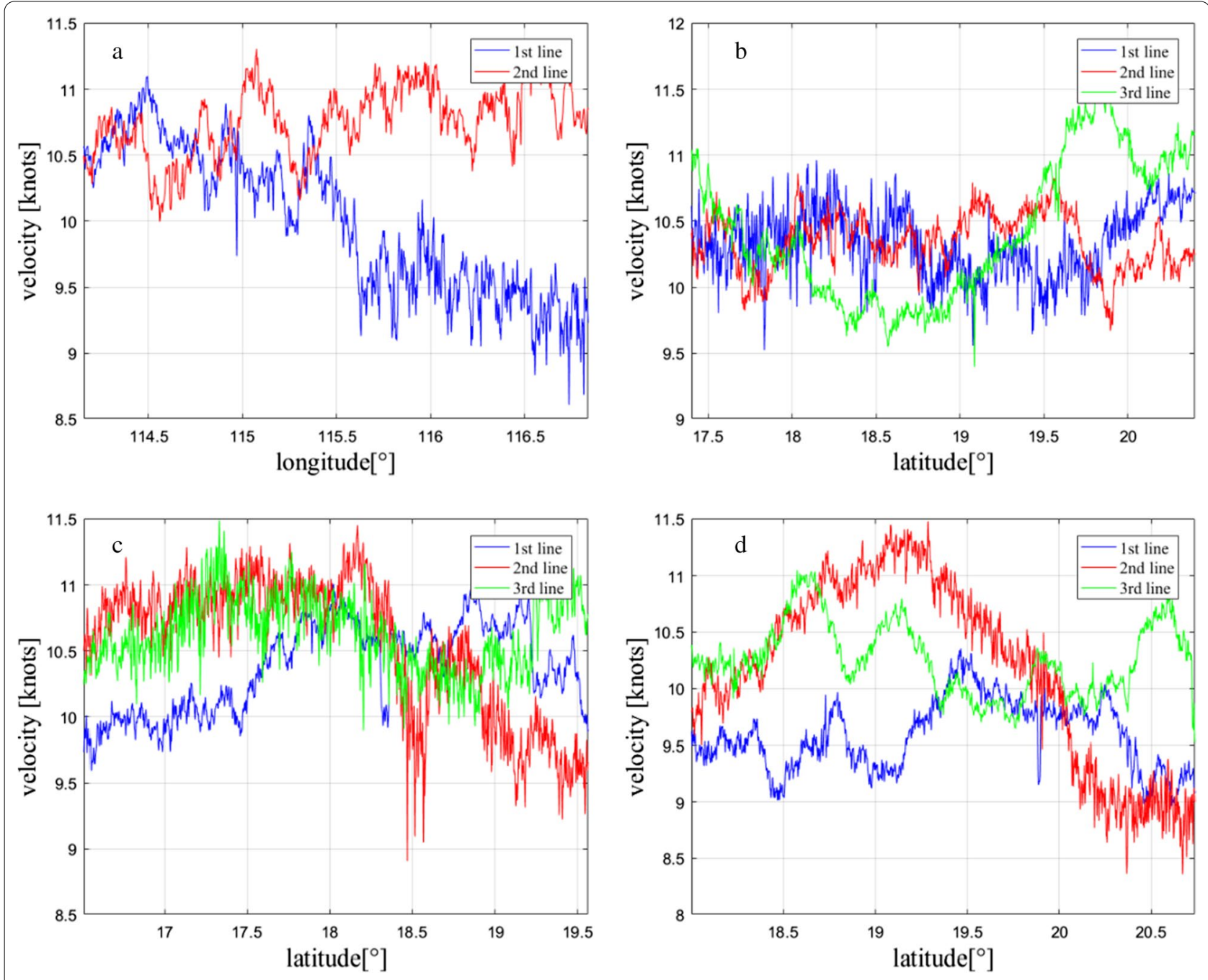

Fig. 6 The speed of the ship: a for $\mathrm{H1}$, $\mathbf{b}$ for $\mathrm{S} 1, \mathbf{c}$ for $\mathrm{X} 1$, and $\mathbf{d}$ for $\mathrm{X} 2$. The speed is somewhere between 9 and 11 knots

\section{Speed comparison before and after correction}

The horizontal velocity error is the main influencing factor in the calculation of the Eötvös correction. In gravimetry, the low-frequency domain should be of interest. As Fig. 12 shows, the horizontal velocity is greatly improved in the time domain; in the frequency domain, waves cause the ship to sway at a high frequency $(0.08-0.22 \mathrm{~Hz})$, and the gravimeters are less affected than the GNSS antennas because the former are installed at a lower height. While

Table 4 The speed of repeated lines

\begin{tabular}{lll}
\hline Repeated lines name & Speed (knots) & Speed $(\mathbf{m} / \mathbf{s})$ \\
\hline H1 & 10.3437 & 5.3213 \\
S1 & 10.3545 & 5.3268 \\
X1 & 10.5015 & 5.4025 \\
X2 & 9.9734 & 5.1307 \\
\hline
\end{tabular}

the speeds of these instruments are very different in the high-frequency band, they do not differ much in the lowfrequency band. Therefore, the Eötvös correction error caused by velocity eccentricities will be small.

\section{Eötvös correction}

As mentioned in "Speed comparison before and after correction" section, the Eötvös corrections are scarcely different when calculated by the velocities before and after in the low-frequency band, but there is a large difference at high frequencies (Fig. 13).

\section{Horizontal acceleration correction}

For gravity measurements, specific force observations in the vertical direction must be acquired. Platform gravimeters need a stable platform to ensure the sensitivity of 


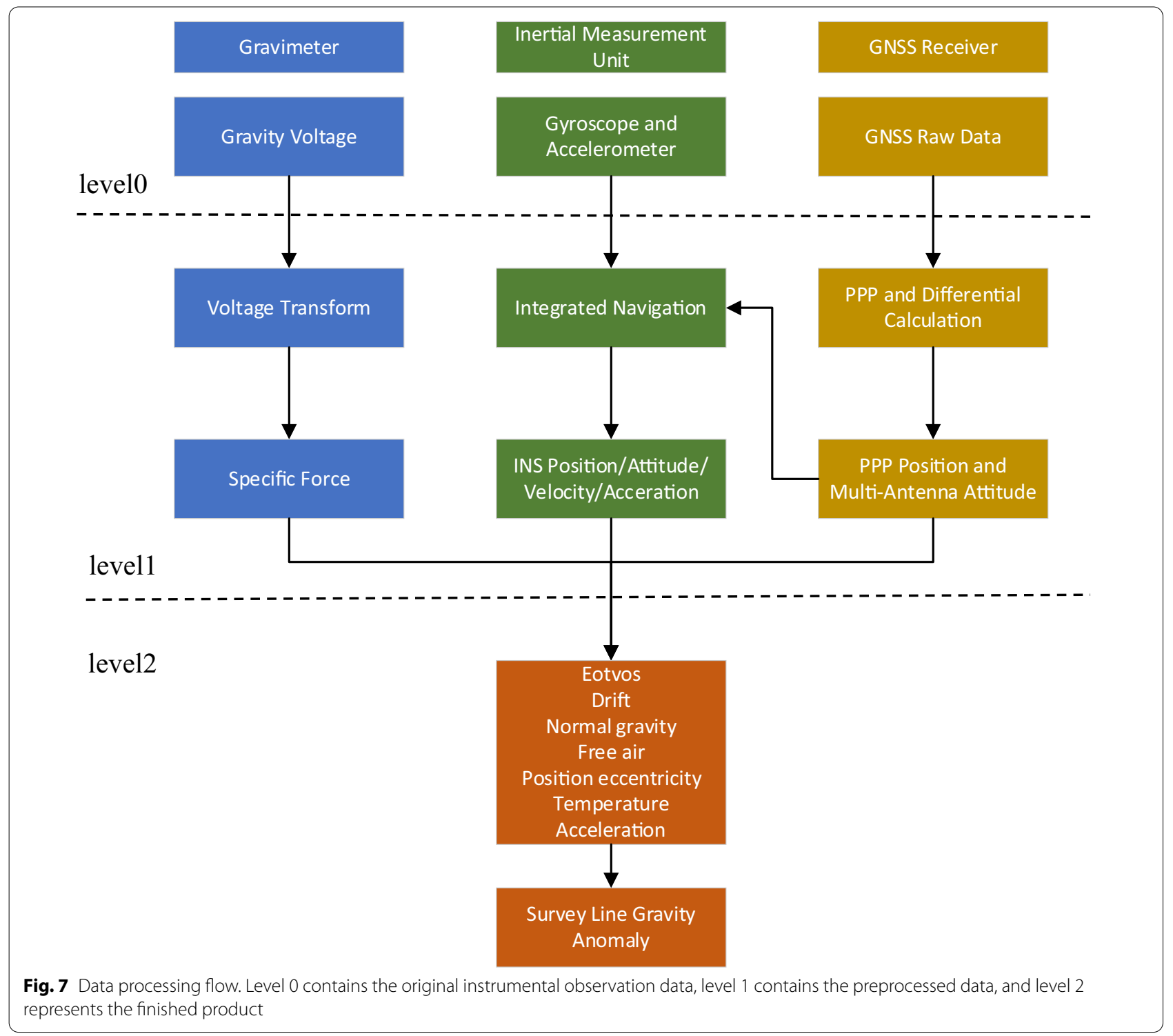

Table 5 The standard deviation of the GNSS antenna array attitude $\left(^{\circ}\right)$

\begin{tabular}{llll}
\hline Line name & Yaw & Pitch & Roll \\
\hline H1-1 & 0.0173 & 0.0359 & 0.1773 \\
H1-2 & 0.0341 & 0.0446 & 0.1635 \\
S1-1 & 0.0247 & 0.0346 & 0.1648 \\
S1-2 & 0.0170 & 0.0326 & 0.1631 \\
S1-3 & 0.0629 & 0.0352 & 0.1652 \\
X1-1 & 0.0174 & 0.0331 & 0.1701 \\
X1-2 & No data & No data & No data \\
X1-3 & 0.0354 & 0.0449 & 0.1814 \\
X2-1 & 0.0323 & 0.0346 & 0.1570 \\
X2-2 & 0.0324 & 0.0325 & 0.1644 \\
X2-3 & 0.0259 & 0.0335 & 0.1648 \\
Mean & 0.0299 & 0.0361 & 0.1671 \\
\hline
\end{tabular}

their internal unit pointing in the vertical direction, while strapdown gravimeters need to measure the attitude of the instrument in real time to calculate the projection of the triaxial acceleration in the vertical direction. However, certain errors are always encountered in the control of a stabilized platform, and strapdown gravimeter attitude calculations also contain errors. These errors will detrimentally impact the vertical acceleration measurement accuracy and result in an unnecessary horizontal acceleration component; therefore, a horizontal acceleration correction is needed. Moreover, the correction intensity rises as the platform angle and horizontal acceleration increase.

In Fig. 14, we compare the horizontal acceleration changes before and after the eccentricity correction and the sea conditions of the ship lines in. The horizontal 

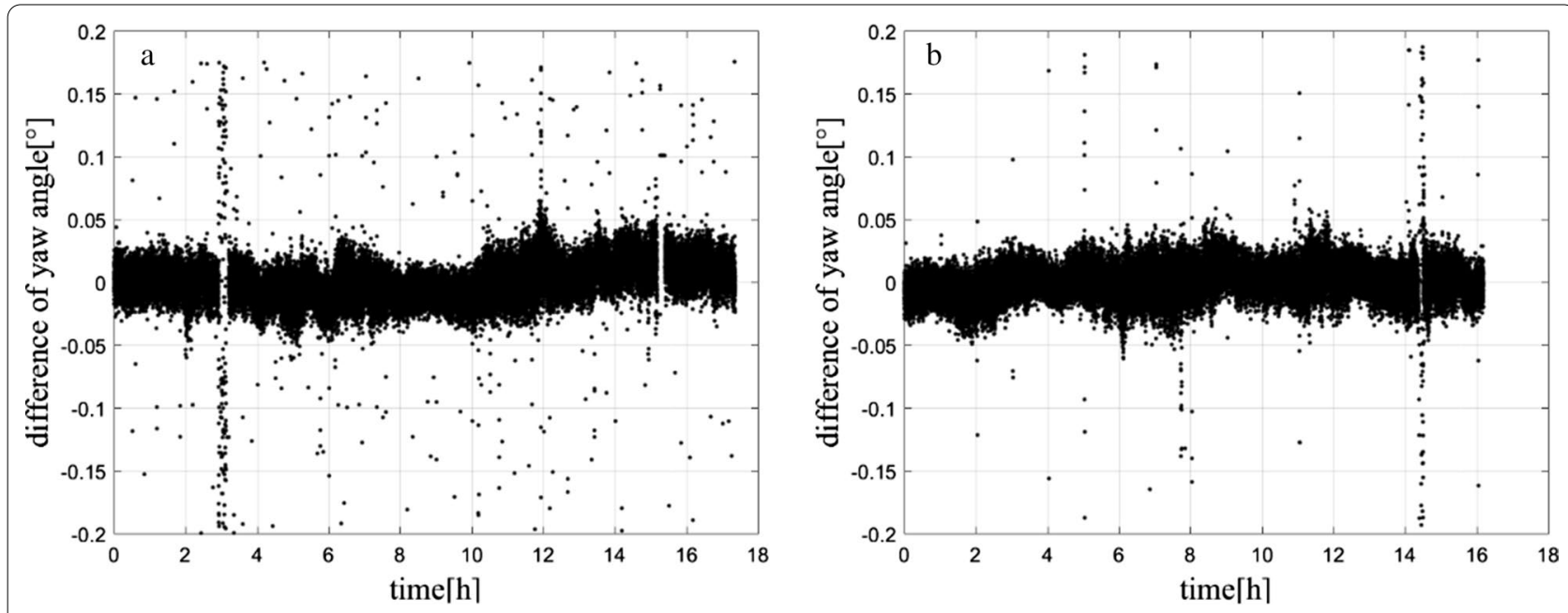

Fig. 8 Difference in the yaw angle: a for S1-1 and b for X1-1
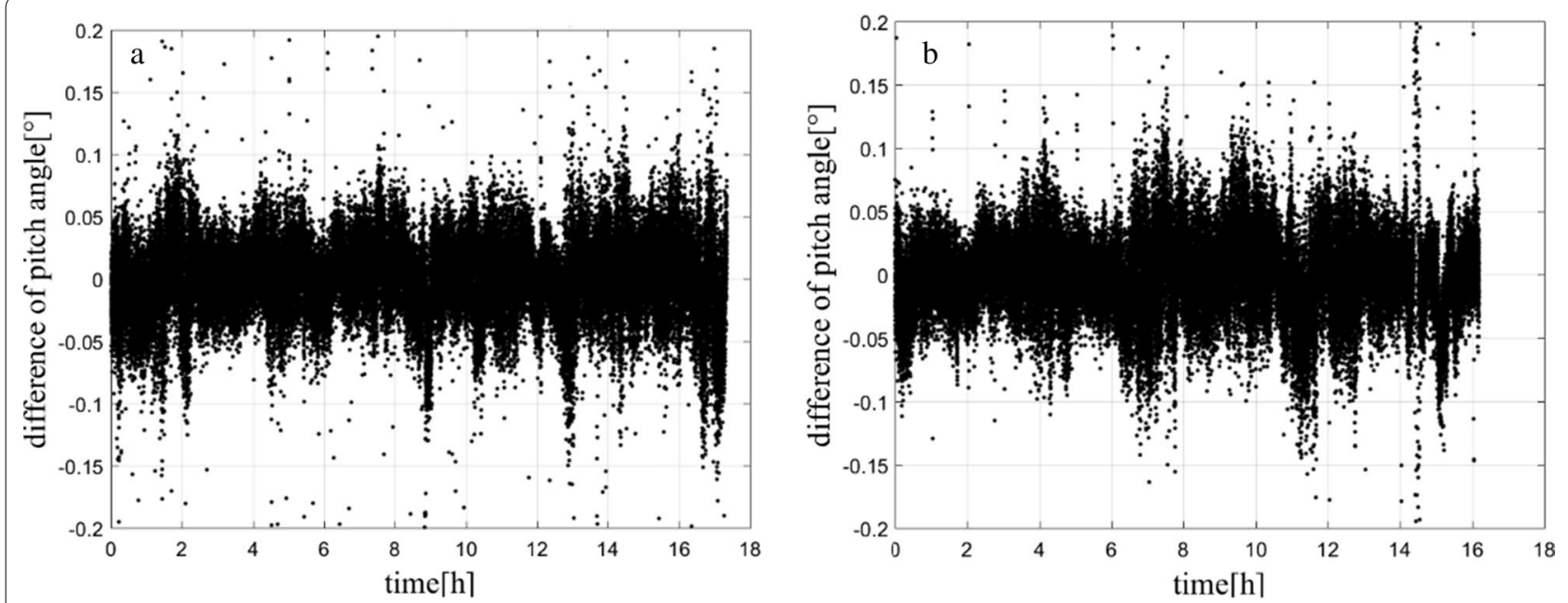

Fig. 9 Difference in the pitch angle: a for $\mathrm{S} 1-2$ and $b$ for $\mathrm{X} 1-1$

acceleration changes obviously after the eccentricity correction and behaves differently at the lower frequencies where the gravity signal is located.

\section{Vertical acceleration correction}

In marine gravimetry, the vertical acceleration is generally considered to have little influence on the gravity signal because of the specific measurement environment. However, the vertical acceleration is a necessary correction in airborne gravimetry (Schwarz and Li 1997; Krasnov et al. 2014). In this paper, the vertical acceleration signal of a marine gravity survey is analyzed, and the necessity of its correction and the influence of the eccentricity correction on the vertical acceleration are analyzed.
Figure 15 reveals that the change in the vertical acceleration after the eccentricity correction is not as great as the change in the horizontal acceleration in the time domain, and the same is true in the frequency domain. However, the horizontal and vertical accelerations both exhibit considerable changes in the low-frequency band.

The main change is in the vertical acceleration calculated by the antenna position, as it has a larger amplitude in the low-frequency band than the vertical acceleration corrected by the eccentricity. However, the vertical acceleration signal in the low-frequency band should be smaller in ocean gravity measurements, so the vertical acceleration should not be corrected during postprocessing. Furthermore, because the vertical 

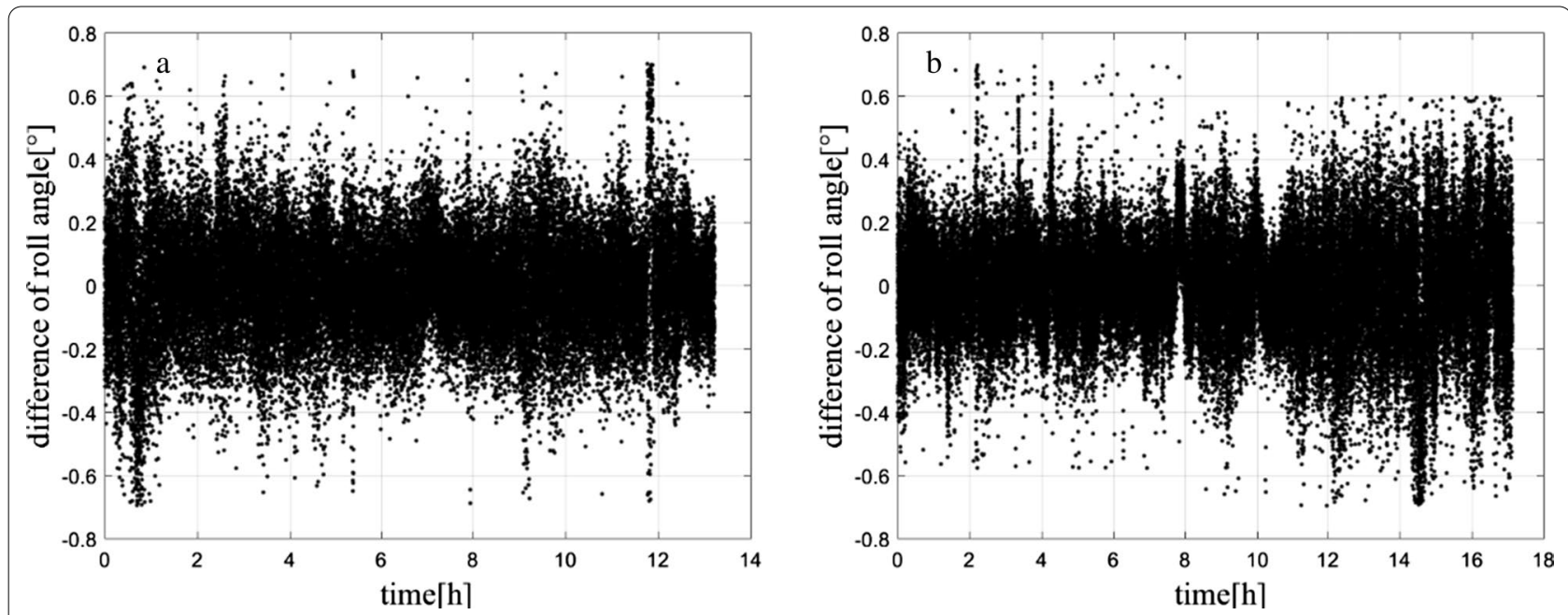

Fig. 10 The difference in the roll angle: a for $\mathrm{H} 1-2$ and $b$ for $X 2-3$

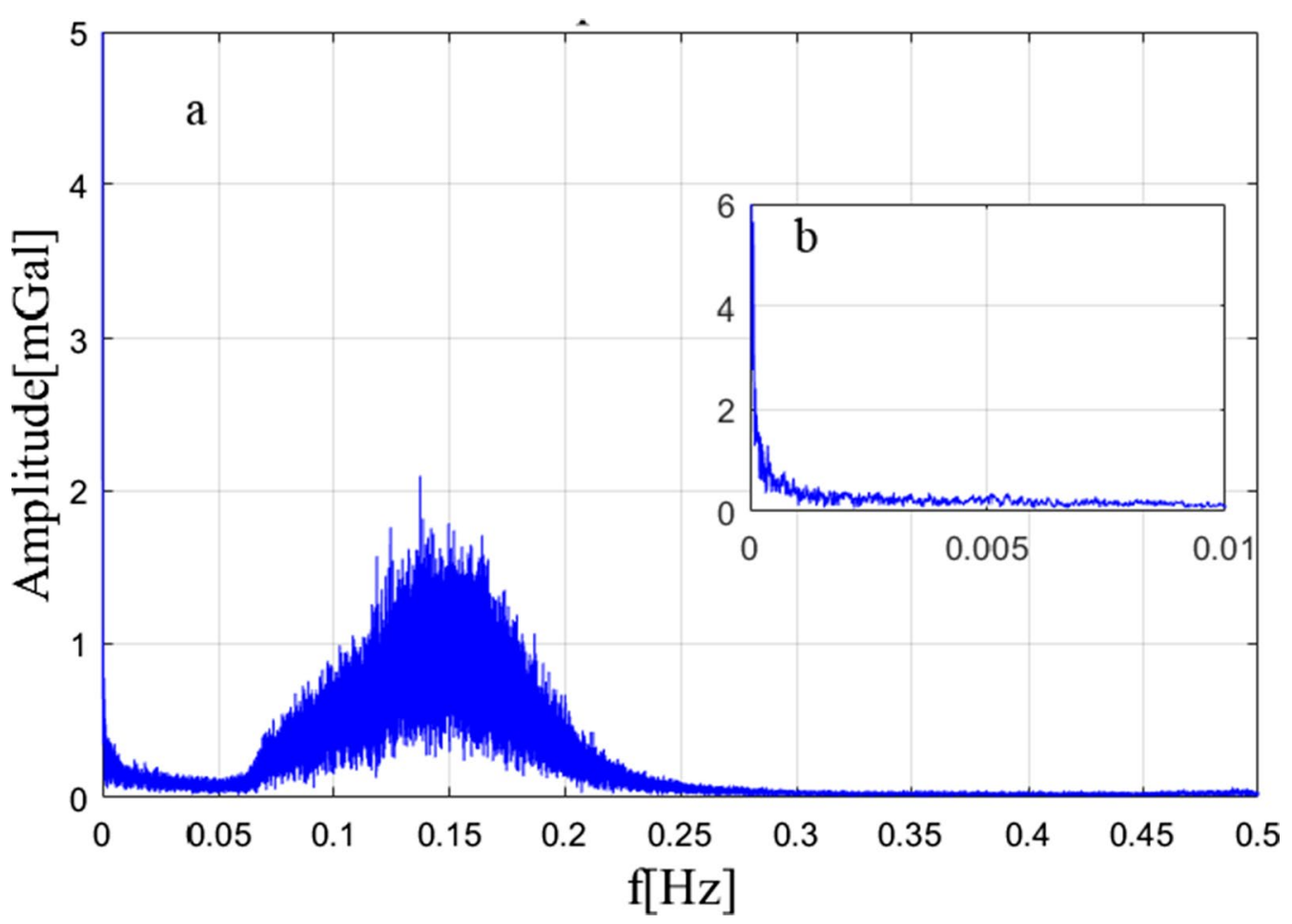

Fig. 11 a Fourier time-frequency analysis of the specific force of the entire voyage. $\mathbf{b}$ Enlarged view of the low-frequency band of $\mathbf{a}$

acceleration after the eccentricity correction obtained by postprocessing is different in the low-frequency band from the vertical acceleration before the correction (at the same antenna position), in airborne gravimetry, it is necessary to carry out the eccentricity correction before the vertical acceleration correction.

\section{Free air correction}

The free air correction adjusts the normal ellipsoid vertical gravity gradient. The free air correction values are approximately $1 \mathrm{mGal}$ for $3 \mathrm{~m}$. As shown in Fig. 16, the eccentricity causes an elevation deviation of approximately $4.3 \mathrm{~m}$, which will result in an absolute error of 

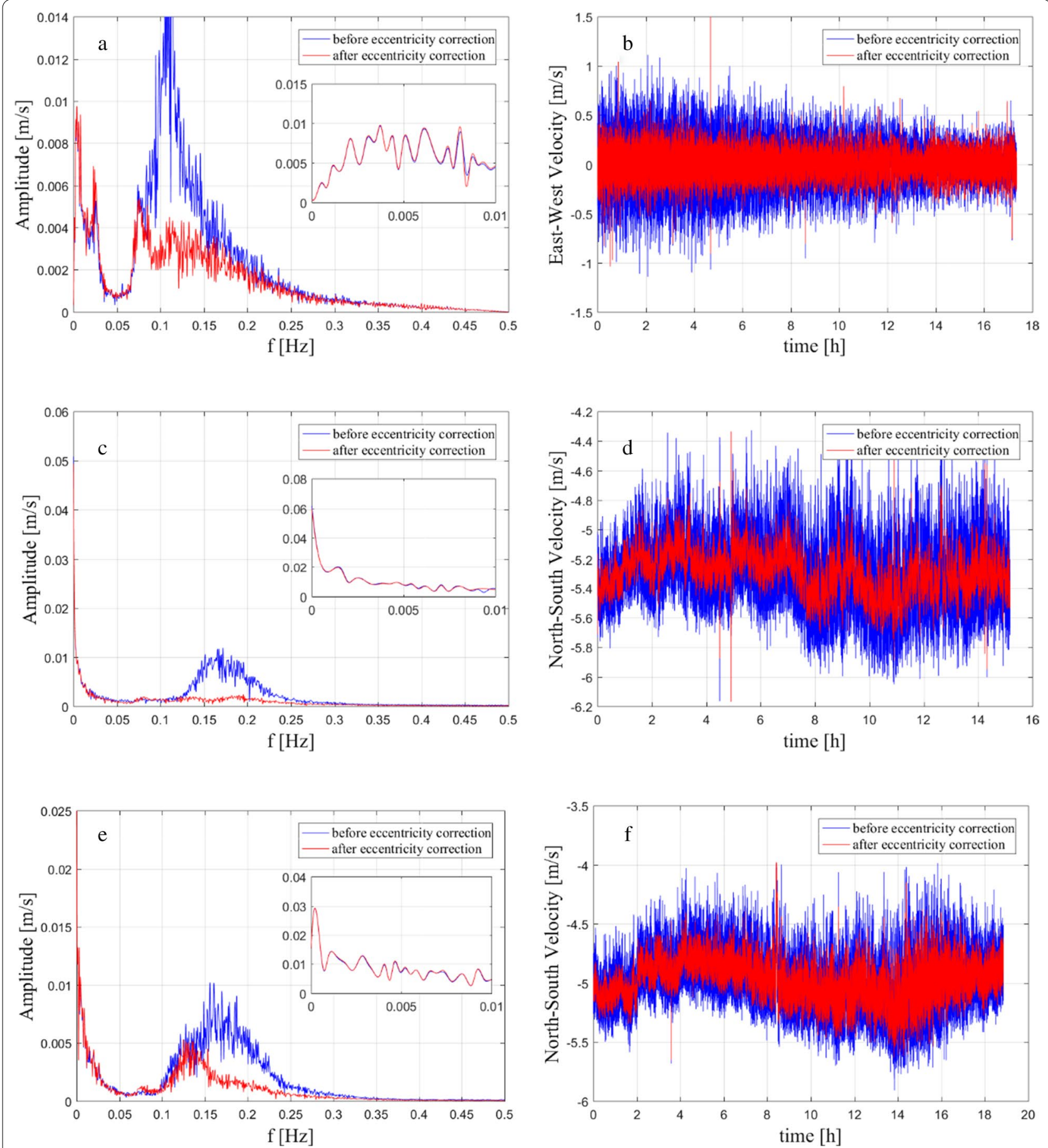

Fig. 12 Fourier time-frequency analysis of horizontal velocities. $\mathbf{a}, \mathbf{c}$ and $\mathbf{e}$ are the single-sided amplitude spectra of the horizontal velocities of S1-2, S1-1 and X1-3, respectively; the small windows are enlarged views of the low-frequency band. $\mathbf{b}, \mathbf{d}$, and $\mathbf{f}$ are the corresponding time-domain horizontal velocities

$1.32 \mathrm{mGal}$ in gravity measurements. If using the average as the offset, the vertical eccentricity will still result in an error of approximately $0.3 \mathrm{~m}(0.1 \mathrm{mGal})$.

\section{Discussion and conclusion}

\section{Precision statistics of repeat lines and crossover points}

In this section, we calculate the maximum (Max.), minimum (Min.), average (Mean.), and root mean square 

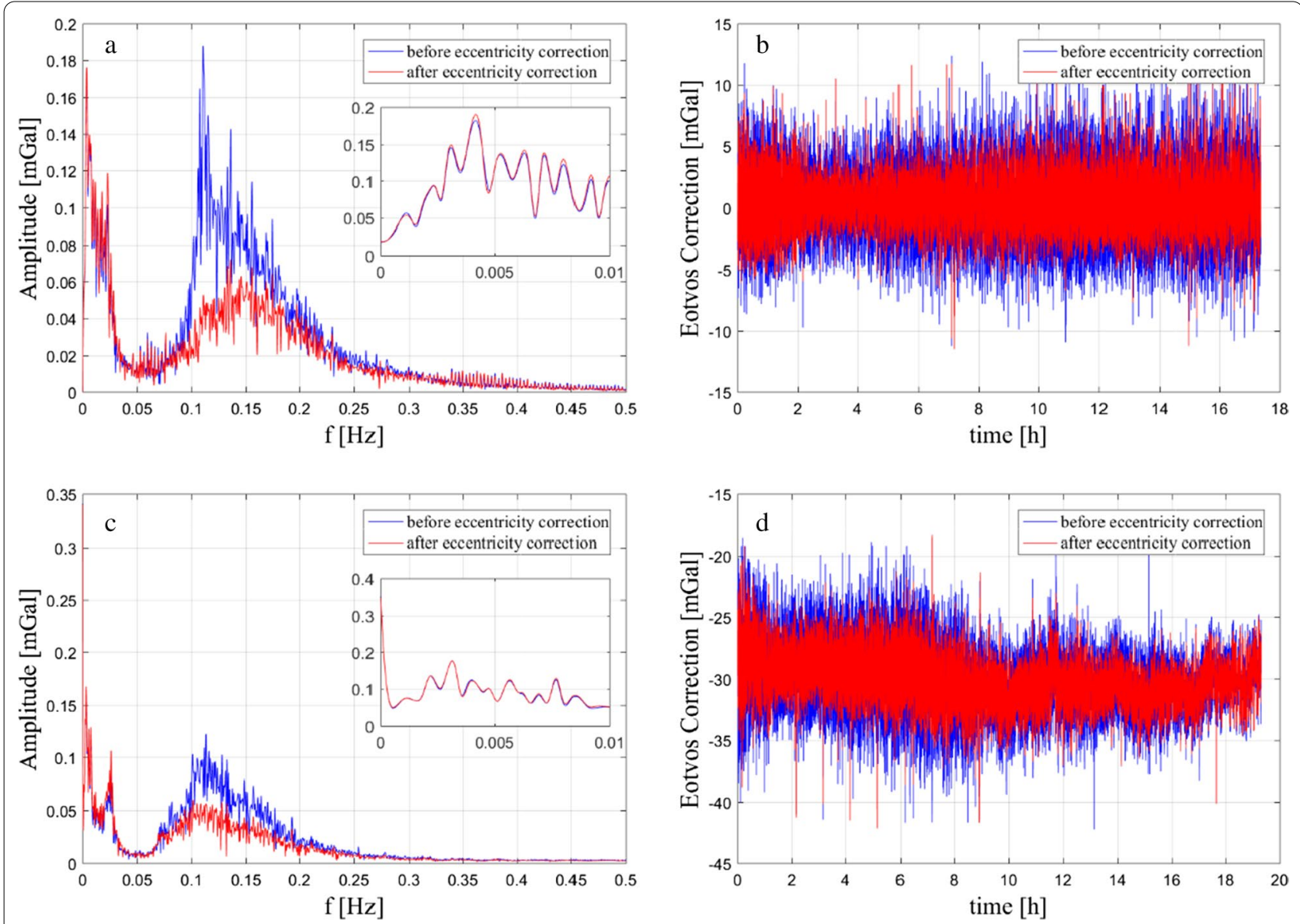

Fig. 13 Fourier time-frequency analysis of Eötvös corrections. a and c are the single-sided amplitude spectra of the Eötvös corrections of S1-1 and $\mathrm{X} 1-1$, respectively; the small windows are enlarged views of the low-frequency band. $b$ and $d$ are the corresponding time-domain Eötvös corrections

Table 6 Statistical results of GT-2M (mGal)

\begin{tabular}{|c|c|c|c|c|c|c|c|c|}
\hline & \multicolumn{4}{|c|}{ Real time } & \multicolumn{4}{|c|}{ Postprocessing } \\
\hline & Min & Max & Mean & RMS & Min & Max & Mean & RMS \\
\hline $\mathrm{H} 1-1-2$ & -2.434 & 3.941 & 0.175 & 0.607 & -0.846 & 0.546 & -0.060 & 0.209 \\
\hline S1-1-2 & -2.526 & 2.102 & -0.107 & 0.538 & -1.073 & 1.225 & 0.062 & 0.304 \\
\hline S1-1-3 & -2.218 & 2.177 & 0.220 & 0.407 & -0.751 & 1.042 & 0.070 & 0.162 \\
\hline S1-2-3 & -2.407 & 2.931 & 0.334 & 0.669 & -1.229 & 1.003 & 0.013 & 0.228 \\
\hline$X 1-1-2$ & -2.530 & 2.800 & -0.585 & 0.630 & -1.354 & 0.906 & -0.154 & 0.326 \\
\hline$X 1-1-3$ & -2.282 & 1.459 & -0.603 & 0.639 & -1.310 & 0.747 & -0.098 & 0.286 \\
\hline$x 1-2-3$ & -1.699 & 1.381 & -0.025 & 0.468 & -0.589 & 0.689 & 0.053 & 0.161 \\
\hline$\times 2-1-2$ & -1.211 & 3.456 & 0.492 & 0.588 & -0.473 & 0.949 & 0.238 & 0.204 \\
\hline$\times 2-1-3$ & -1.699 & 2.151 & 0.097 & 0.448 & -0.906 & 0.774 & -0.145 & 0.209 \\
\hline$\times 2-2-3$ & -2.418 & 1.550 & -0.397 & 0.520 & -1.528 & 0.458 & -0.387 & 0.333 \\
\hline Crossover points & -1.874 & 1.152 & -0.021 & 0.527 & -0.566 & 0.755 & -0.073 & 0.248 \\
\hline Mean & -2.118 & 2.282 & -0.038 & 0.549 & -0.966 & 0.827 & -0.044 & 0.243 \\
\hline
\end{tabular}



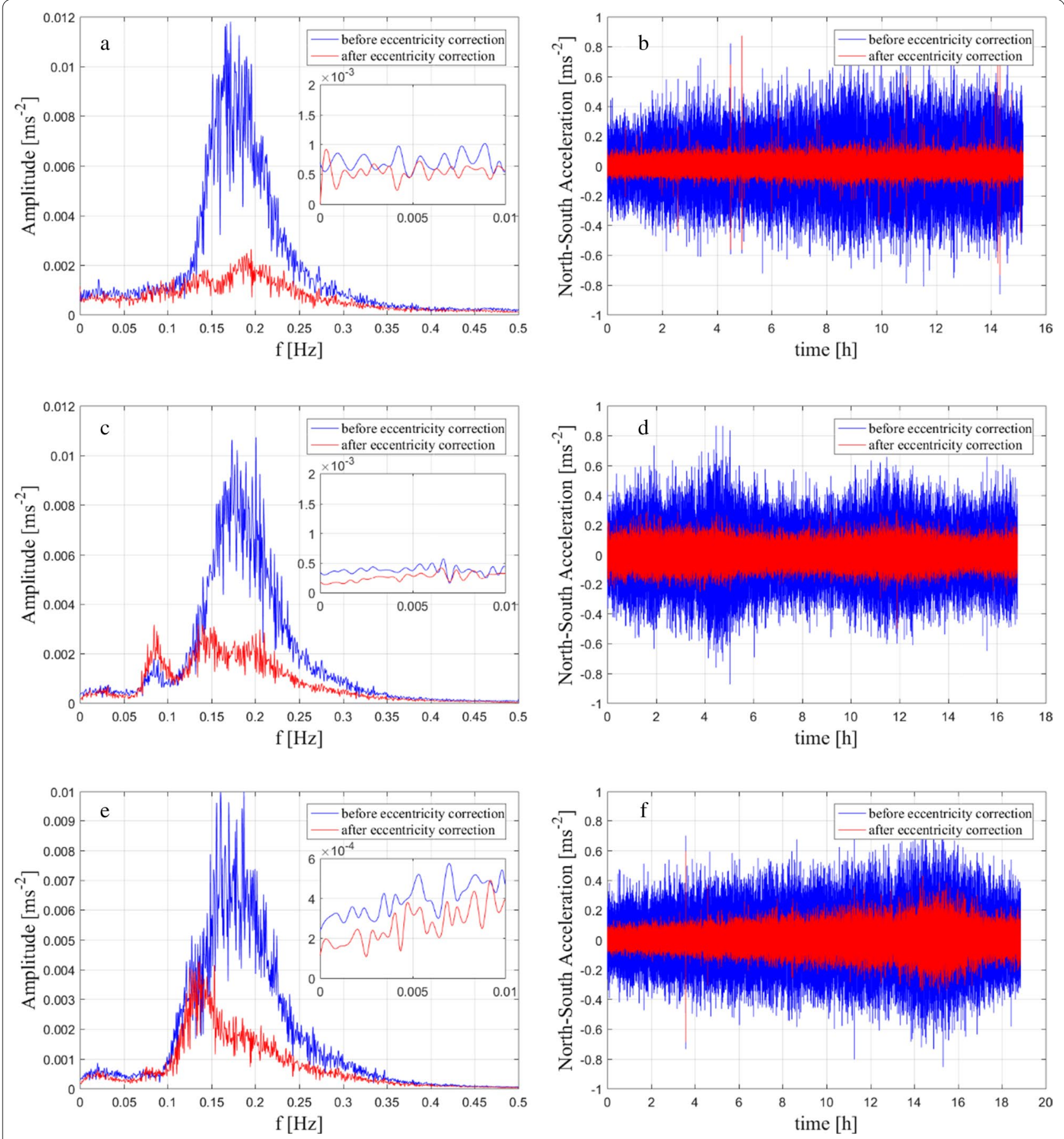

Fig. 14 Fourier time-frequency analysis of horizontal accelerations. a, $\mathbf{c}$ and $\mathbf{e}$ are the single-sided amplitude spectra of the horizontal accelerations of $\mathrm{S} 1-1, \mathrm{X} 1-2$ and $\mathrm{X} 1-3$, respectively; the small windows are enlarged views of the low-frequency band. $\mathbf{b}, \mathbf{d}$, and $\mathbf{f}$ are the corresponding time-domain horizontal accelerations

(RMS.) of the measurement error for each repeated line. The statistical results are shown in the tables below. The notation H1-1-2 indicates the difference between the first and second lines of $\mathrm{H} 1$.
As shown in Tables 6 and 7, the accuracy of gravimeters GT and SAG is improved because of the low measurement noise of the instruments. However, in Table 8, the improvement in the measurement accuracy is not 

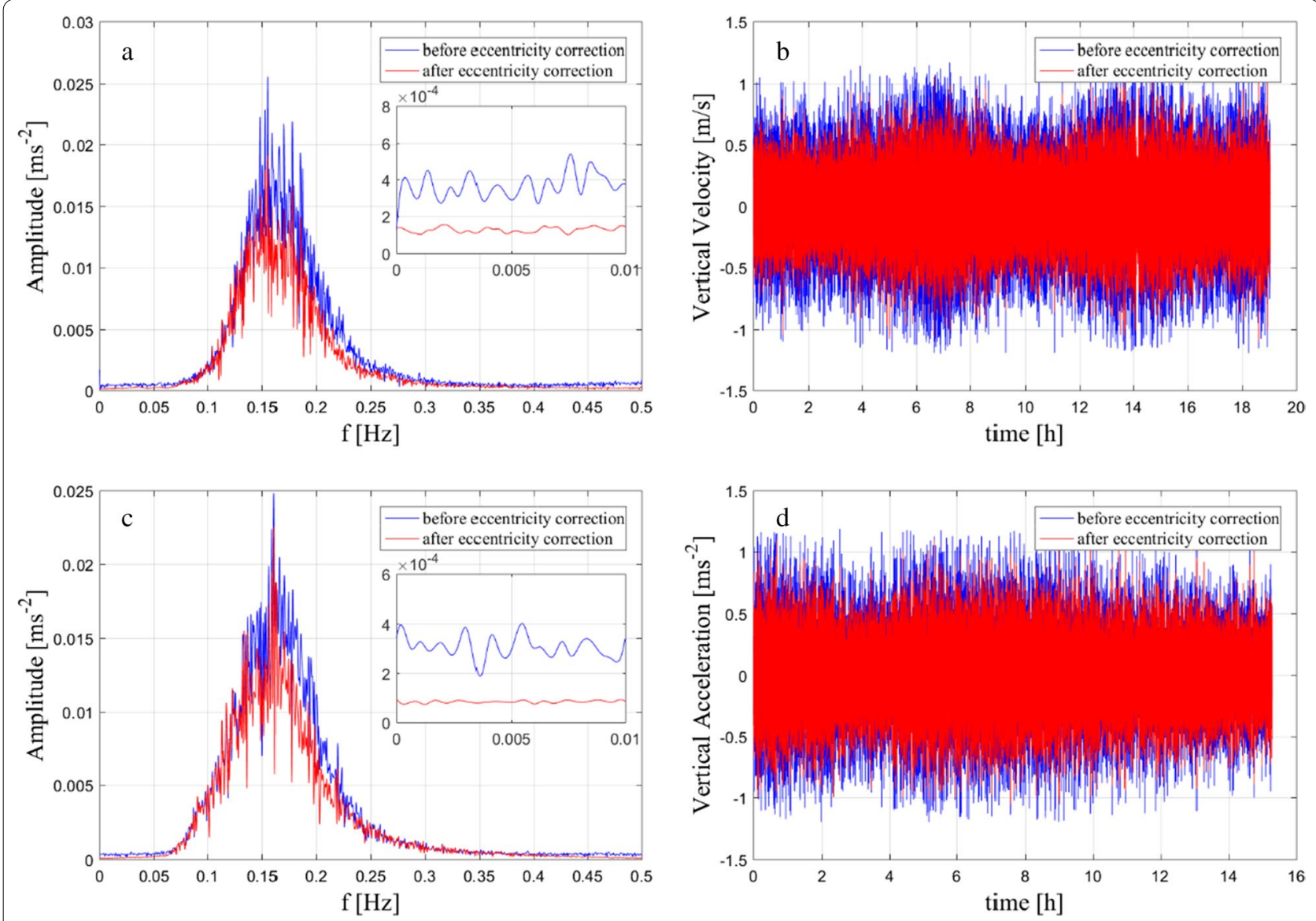

Fig. 15 Fourier time-frequency analysis of vertical accelerations. $\mathbf{a}$ and $\mathbf{c}$ are the single-sided amplitude spectra of the vertical acceleration of X1-3 and $\mathrm{H1} 1$-1, respectively; the small windows are enlarged views of the low-frequency band. $\mathbf{b}$ and $\mathbf{d}$ are the corresponding time-domain vertical accelerations

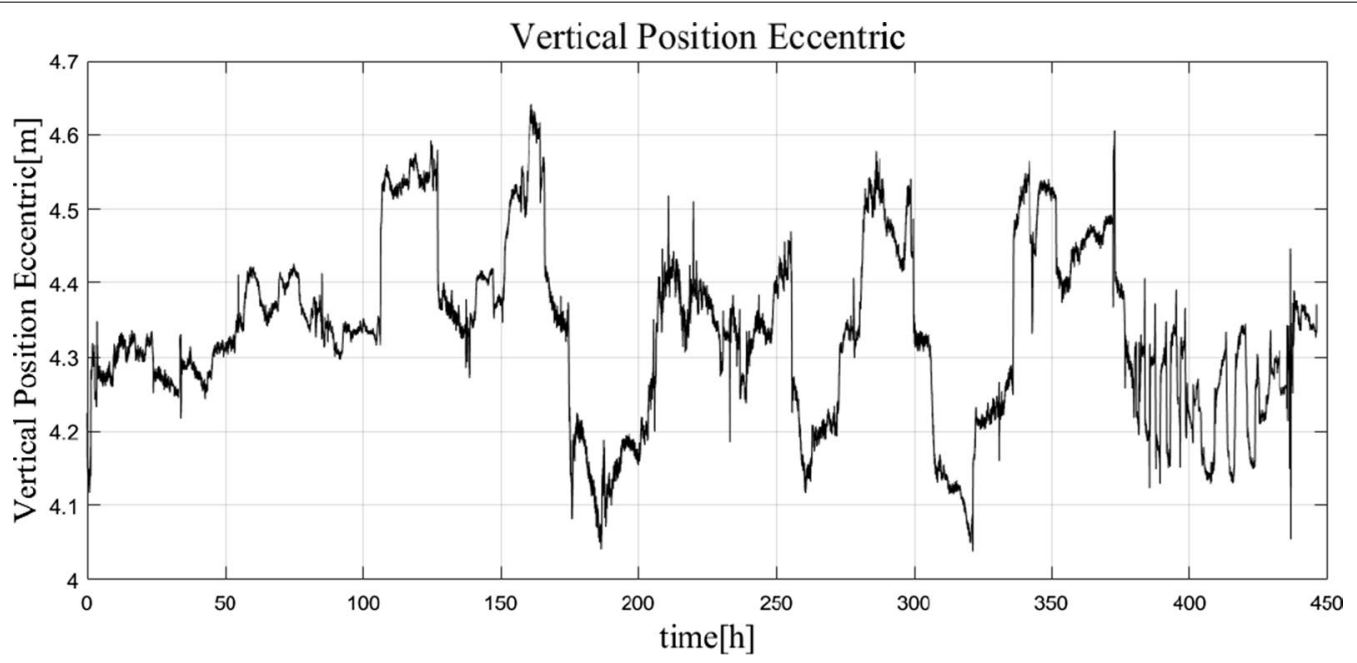

Fig. 16 Elevation eccentricity of the whole voyage 
Table 7 Statistical results of SAG-2M (mGal)

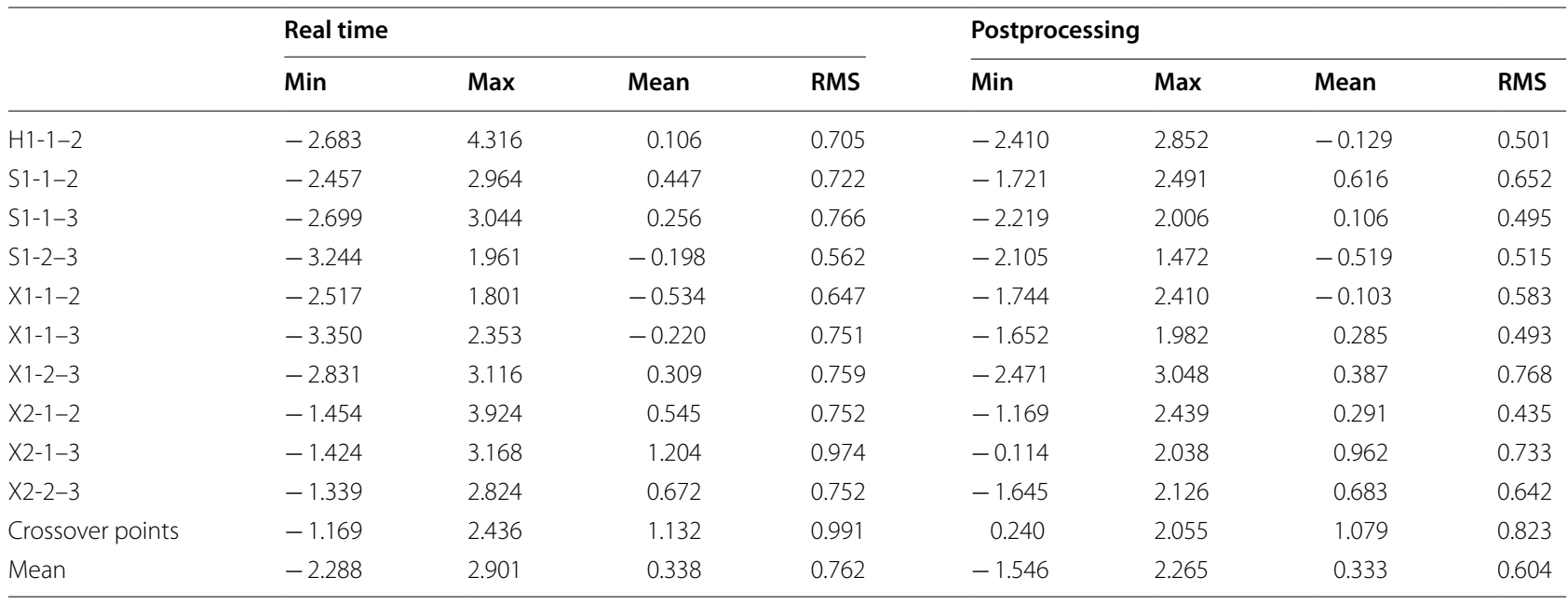

Table 8 Statistical results of L\&R (mGal)

\begin{tabular}{|c|c|c|c|c|c|c|c|c|}
\hline & \multicolumn{4}{|l|}{ Real time } & \multicolumn{4}{|c|}{ Postprocessing } \\
\hline & Min & Max & Mean & RMS & Min & Max & Mean & RMS \\
\hline $\mathrm{H} 1-1-2$ & -12.501 & 7.645 & -0.430 & 2.175 & -12.461 & 6.029 & -0.638 & 2.168 \\
\hline $\mathrm{S} 1-1-2$ & -4.941 & 5.849 & 0.659 & 1.590 & -6.105 & 5.940 & 0.801 & 1.545 \\
\hline $51-1-3$ & -3.846 & 7.981 & 2.453 & 2.114 & -5.542 & 8.220 & 2.271 & 1.974 \\
\hline S1-2-3 & -2.210 & 7.790 & 1.814 & 1.856 & -2.264 & 6.687 & 1.487 & 1.616 \\
\hline$x 1-1-2$ & -12.603 & 13.359 & -0.919 & 2.710 & -14.718 & 12.463 & -0.444 & 2.476 \\
\hline$X 1-1-3$ & -18.201 & 40.947 & 1.425 & 3.695 & -19.101 & 41.010 & 1.949 & 3.803 \\
\hline$x 1-2-3$ & -9.257 & 40.823 & 2.347 & 3.629 & -8.763 & 41.218 & 2.400 & 3.509 \\
\hline$\times 2-1-2$ & -1.492 & 8.317 & 3.508 & 2.769 & -0.864 & 6.985 & 3.241 & 2.526 \\
\hline$\times 2-1-3$ & -9.778 & 3.762 & -1.653 & 2.118 & -9.985 & 3.653 & -1.910 & 2.170 \\
\hline$\times 2-2-3$ & -11.772 & 1.430 & -5.233 & 4.202 & -12.310 & 2.189 & -5.223 & 4.185 \\
\hline Crossover points & -0.733 & 7.460 & 2.549 & 2.463 & -0.729 & 7.017 & 2.502 & 2.342 \\
\hline Mean & -7.939 & 13.215 & 0.593 & 2.666 & -8.440 & 12.856 & 0.585 & 2.574 \\
\hline
\end{tabular}

obvious because the correction is obscured by the measurement noise of the instrument.

\section{Conclusion}

Concerning the proposed postprocessing method for gravity calculations using the GNSS antenna array attitude positioning method, the following conclusions are obtained:

1. The determination of an instrument's position and attitude using a GNSS antenna array is an efficient, low-cost and high-precision method. In marine gravimetry, the advantages of the ship's large size and long baseline can be utilized to obtain a more accurate attitude, and the marine measurement environment is free of shielding effects; hence, the measurement stability can be guaranteed. When the effective baseline length is $25 \mathrm{~m}$ and $4 \mathrm{~m}$, the attitude angle accuracies obtained in this test are $0.0299^{\circ}$ for the yaw angle, $0.0361^{\circ}$ for the pitch angle and $0.1671^{\circ}$ for the roll angle.

2. The eccentricity correction has a great influence on the overall calculation of the horizontal velocity, but it has little influence on the low-frequency part corresponding to the gravity signal and thus has little influence on the calculation of the Eötvös correction in gravity measurements. 
3. The horizontal acceleration after implementing the eccentricity correction exhibits obvious changes in both the low-frequency and the high-frequency parts, especially under poor sea conditions. Therefore, the eccentricity correction should be carried out first when the horizontal acceleration correction is considered in gravity measurement. The vertical acceleration does not change obviously in the highfrequency band, but displays considerable variation in the low-frequency band. Hence, the eccentricity correction should be carried out first when the vertical acceleration is corrected in airborne gravity data, but can be ignored in marine gravity surveying.

4. The absolute error of the free air correction caused by the position eccentricity is large (at the $\mathrm{mGal}$ level) and thus cannot be ignored in marine and airborne gravity measurements. If the correction is carried out with a constant value, an error on the scale of $10^{-1} \mathrm{mGal}$ will remain, which should be considered in gravity measurements. Measured data show that the relative accuracy of gravity data can be steadily improved by $0.02 \mathrm{mGal}$ after applying the eccentricity correction in this experiment.

5. The method of using a GNSS antenna array can obviously improve the measurement accuracy of instruments with a precision equal to or exceeding $1 \mathrm{mGal}$, but this approach is not effective for instruments with poor precision ( $2 \mathrm{mGal}$ or below).

\begin{abstract}
Abbreviations
EGM-96: 1996 Earth Gravitational Model; FIR: Finite-impulse response; GNSS: Global Navigation Satellite System; GPS: Global Positioning System; Max: Maximum; Min: Minimum; PPP: Precise point positioning; RMS: Root mean square; SINS: Strapdown Inertial Navigation System.
\end{abstract}

\section{Acknowledgements}

We are grateful to Dr. Yuan Yuan for providing the gravity data and Dr. Xiaowen Luo for providing the GNSS data work at the Second Institute of Oceanography, Ministry of Natural Resources, Hangzhou 310012, China.

\section{Authors' contributions}

In this work, $L L, X L, A G$ and $J L$ proposed idea. JL conducted experiment and collected data. $Z S$ processed data and wrote the draft. $Z Z, X L, A G, Z S$ and $J L$ discussed the result. $X \mathrm{~L}, A G$, and $Z Z$ revised the manuscript. All authors read and approved the final manuscript.

\section{Funding}

This article was not supported by funding.

\section{Availability of data and materials}

The data that support the findings of this study are from the Second Institute of Oceanography, Ministry of Natural Resources, Hangzhou 310012, China, with permission, but restrictions apply to the availability of these data due to confidentiality of test tasks, and so are not publicly available. Data are available from the authors upon reasonable request and with permission of the Second Institute of Oceanography, Ministry of Natural Resources, Hangzhou 310012, China. Questions and requests for materials can be addressed to shizhimin@ whigg.ac.cn or Ixh_whigg@asch.whigg.ac.cn. We will consult with the Second Institute of Oceanography, Ministry of Natural Resources, Hangzhou 310012, China, when necessary.

\section{Declarations}

\section{Competing interests}

The authors declare that they have no competing interests.

\section{Author details}

${ }^{1}$ State Key Laboratory of Geodesy and Earth's Dynamics, Innovation Academy for Precision Measurement Science and Technology, Chinese Academy of Sciences, Wuhan 430077, China. ${ }^{2}$ University of Chinese Academy of Science, Beijing 100049, China.

Received: 8 May 2021 Accepted: 14 August 2021

Published online: 30 August 2021

\section{References}

Aleshechkin AM (2011) Algorithm of GNSS-based attitude determination. Gyrosc Navig 2(4):269

Cai S, Tie J, Zhang K, Cao J, Wu M (2017) Marine gravimetry using the strapdown gravimeter SGA-WZ. Mar Geophys Res 38(4):325-340. https:// doi.org/10.1007/s11001-017-9312-9

Cai XB, Hsu HS, Chai H, Ding LX, Wang Y (2018) Multi-antenna GNSS and INS integrated position and attitude determination without base station for land vehicles. J Navig 72(2):342-358. https://doi.org/10.1017/s0373 463318000681

Dodson AH, Moore T, Chen W, Oehl H, Houghton P, Ion (1997) Precise GPS for integrated marine gravity acquisition. In: 10th international technical meeting of the satellite division of the institute-of-navigation, Kansas City Convent CTR, Kansas City, MO, SEP 16-19, 1997, 937-944

Dong Y, Zhang L, Wang DJ, Li QS, Wu J, Wu MK (2020) Low-latency, highrate, high-precision relative positioning with moving base in real time. Gps Solut. https://doi.org/10.1007/s10291-020-0969-1

Ebbing J, Bouman J, Fuchs M, Lieb V, Haagmans R, Meekes J, Fattah RA (2013) Advancements in satellite gravity gradient data for crustal studies. Lead Edge 8:900-906

Harlan RB (1968) Eötvös correction for airborne gravimetry. J Geophys Res. https://doi.org/10.1029/JB073i014p04675

Hehl K (1992) Bestimmung von Beschleunigungen auf einem bewegten Trager durch GPS und Digitale Filterung. Universit"at der Bundeswehr Mǜnchen, Mǜnchen

Heroux P, Kouba J (2001) GPS precise point positioning using IGS orbit products. Phys Chem Earth Part a-Solid Earth Geod 26(6-8):573-578. https://doi.org/ 10.1016/s1464-1895(01)00103-x

Hu P, Zhao M, Huang H, Liu D, Tang J, Wei C (2017) Review on the development of airborne/marine gravimetry instruments. Navig Position Tim 4:10-19

Huang MT (1995) Marine gravity surveying line system adjustment. J Geod 70(3):158-165. https://doi.org/10.1007/bf00943691

Hwang C, Hsu HJ, Chang ETY, Featherstone WE, Tenzer R, LienT JPH (2014) New free-air and Bouguer gravity fields of Taiwan from multiple platforms and sensors. Tectonophysics 611:83-93. https://doi.org/10.1016/j.tecto.2013.11. 027

Ishihara T, Shinohara M, Fujimoto H, Kanazawa T, Araya A, Yamada T, Uehira K (2018) High-resolution gravity measurement aboard an autonomous underwater vehicle. Geophysics 83(6):G119-G135. https://doi.org/10.1190/ geo2018-0090.1

Jekeli C (2012) Inertial Navigation Systems with Geodetic Applications. De Gruyter

Krasnov AA, Sokolov AV, Elinson LS (2014) Operational experience with the Chekan-AM gravimeters. Gyroscopy and Navigation 5(3):181-185

Lacoste L (1967) Measurement of gravity at sea and in air. Rev Geophys 5(4):477. https://doi.org/10.1029/RG005i004p00477

Lacoste L, Bowles R (1982) Gravity measurements in an airplane using state-ofthe-art navigation and altimetry. Geophysics 47:832-838 
Lavrov D, Even TG, Reinking J (2017) Expansion and improvement of the Israeli geoid model by shipborne GNSS measurements. J Surv Eng. https://doi. org/10.1061/(asce)su.1943-5428.0000204

Li HJ, Wang JX, Chen JP, Hu CW, Wang H (2010) The realization and analysis of GNSS network based real-time precise point positioning. Chin J Geophys Chin Ed 53(6):1302-1307

Li XX, Ge MR, Zhang HP, Nischan T, Wickert J (2013) The GFZ real-time GNSS precise positioning service system and its adaption for COMPASS. Adv Space Res 51(6):1008-1018. https://doi.org/10.1016/j.asr.2012.06.025

Liang XH (2012) Method and experiment research on airborne gravimetry. (Doctor of Geodesy and Surveying Engineering), University of Chinese Academy of Sciences

Liu GY, Ou JK (2003) Determining attitude with single epoch GPS Algorithm and its precision analysis. Geomatics Inf Sci Wuhan Univ 28(6):732-735

Liu M, Huang MT, Ouyang YZ, Deng KL, Zhai GJ, Lu XP, Wu TQ, Chen X (2017) Development and prospect of air-sea gravity survey and its applications, part II: sensor, plan and design of survey. Hydrogr Surv Chart 37:1-11

Ouyang YZ (2013) On Key Technologies of Data Processing for Air-sea Gravity Surveys. (Doctor of Philosophhy), Wuhan University

Ouyang YZ, Deng K, Lu X, Wu T, Yan X, Chang G (2013) Tests of multitype airborne gravimeters and data analysis. Hydrogr Surv Chart 33:6-11

RTKLIB: an Open Source Program Package for RTK-GPS, http://gpspp.sakura.ne.jp/ rtklib/rtklib.htm

Saha SK, Mukherjee S, Mandal D, Kar R, Ghoshal SP (2012) Gravitational search algorithm in digital fir low pass filter design. In: Jana D, Pal P (eds) 2012 third international conference on emerging applications of information technology. IEEE, New York. pp 52-55

Sandwell DT, Smith WHF (1997) Marine gravity anomaly from Geosat and ERS 1 satellite altimetry. J Geophys Res Solid Earth 102(B5):10039-10054. https:// doi.org/10.1029/96jb03223

Schwarz KP, Li Z (1997) An introduction to airborne gravimetry and its boundary value problems. In: Sansó F, Rummel R (eds) Geodetic boundary value problems in view of the one centimeter geoid. Springer, Berlin, pp 312-358

Sun ZM (2004) Theory, methods and applications of airborne gravimetry. (Doctor of Philosophhy), Information Engineering University.
Sun ZM, Xia ZR, Xiao Y, LiY (2003) Eccentricity correction for airborne gravimetry. Geomatics and Information Science of Wuhan University, S1, pp 65-68

Varbla S, Ellmann A, Delpeche-Ellmann N (2020) Validation of marine geoid models by utilizing hydrodynamic model and shipborne GNSS profiles. Mar Geod 43(2):134-162. https://doi.org/10.1080/01490419.2019.1701153

Vening Meinesz FA(1929) Theory and practice of pendulum observations at sea, vol I and II, Publications of the Netherlands Geodetic Commission, Delft, 1929 and 1941

Wang W, Gao JY, Li DM, Zhang T, Luo XW, Wang JL (2018) Measurements and accuracy evaluation of a strapdown marine gravimeter based on inertial navigation. Sensors 18(11):3902

Xiao GW, Liu GY, Ou JK, Liu GL, Wang SL, Guo AZ (2020) MG-APP: an open-source software for multi-GNSS precise point positioning and application analysis. GPS Solut 24(3):66. https://doi.org/10.1007/s10291-020-00976-1

Xu HW, Lian BW, He W, Tang CK (2015) A GNSS precise velocity determination algorithm based on chaotic oscillator. IEEE, New York

Yuan Y, Gao Jy WuZC, Shen ZY, Wu GC (2020) Performance estimate of some prototypes of inertial platform and strapdown marine gravimeters. Earth Planets Space 72(1):89. https://doi.org/10.1186/s40623-020-01219-w

Zhang K, Hao JM (2017) Research on BDS/GPS combined single-epoch attitude determination performance. In: Sun J, Liu J, Yang Y, Fan S, Yu W (eds.), China satellite navigation conference, vol 437, pp 23-31.

Zheleznyak LK, Mikhailov PS (2012) Application of GPS data for tidal correction of marine gravity measurements. Izvestiya-Phys Solid Earth 48(6):547-549. https://doi.org/10.1134/s1069351312060092

Zhu CC, Guo JY, Hwang C, Gao JY, Yuan JJ, Liu X (2019) How HY-2A/GM altimeter performs in marine gravity derivation: assessment in the South China Sea. Geophys J Int 219(2):1056-1064. https://doi.org/10.1093/gji/ggz330

\section{Publisher's Note}

Springer Nature remains neutral with regard to jurisdictional claims in published maps and institutional affiliations.

\section{Submit your manuscript to a SpringerOpen ${ }^{\circ}$ journal and benefit from:}

- Convenient online submission

- Rigorous peer review

- Open access: articles freely available online

- High visibility within the field

- Retaining the copyright to your article

Submit your next manuscript at springeropen.com 